\title{
CONTRIBUIÇÃO PARA O CONHECIMENTO DA GEOMORFOLOGIA DA CADEIA DA ARRÁBIDA (PORTUGAL): CARTOGRAFIA GEOMORFOLÓGICA E GEOMORFOMETRIA
}

\section{CONTRIBUTION TO THE KNOWLEDGE OF THE GEOMORPHOLOGY OF THE ARRABIDA CHAIN (PORTUGAL): GEOMORPHOLOGICAL MAPPING AND GEOMORPHOMETRY}

\author{
André Filipe Fonseca \\ Instituto de Geografia e Ordenamento do Território, Universidade de Lisboa \\ Universidade de Lisboa, Lisboa, CEP: 1600-214, Portugal \\ Email:a.fonseca@campus.ul.pt
}

José Luis Zêzere

Instituto de Geografia e Ordenamento do Território, Universidade de Lisboa Universidade de Lisboa, Lisboa, CEP: 1600-214, Portugal Email: zezere@campus.ul.pt

Mário Neves

Instituto de Geografia e Ordenamento do Território, Universidade de Lisboa Universidade de Lisboa, Lisboa, CEP: 1600-214, Portugal

Email:marioneves@campus.ul.pt

\section{Informações sobre o Artigo}

Data de Recebimento:

17/04/2014

Data de Aprovação:

08/08/2014

Palavras-chave:

Serra da Arrábida;

Cartografia Geomorfológica;

Geomorfometria.

Keywords:

Serra da Arrábida; Geomorphological Mapping;

Geomorphometry.

\section{Resumo:}

A cadeia da Arrábida resulta da interação de processos tectónicos e erosivos ao longo de um período de tempo alargado, situado entre o Miocénico médio e a atualidade. $\mathrm{O}$ desmantelamento da cadeia processou-se em função da componente de movimentação tectónica, da posição da linha de costa e dos processos erosivos a ela associados, desempenhando a rede hidrográfica um papel fundamental no restabelecimento do equilíbrio dinâmico entre processos endógenos e exógenos. Esta relação está expressa no escalonamento altitudinal de formas erosivas aplanadas e suspensas sobre a rede de drenagem atual, evidenciando uma evolução policíclica do relevo controlada pelo levantamento da Serra da Arrábida, pela subsidência do Sinclinal de Albufeira e pelas oscilações do nível do mar no decorrer do período plio-quaternário. Sobrepõe-se a este processo o rejogo vertical de falhas de orientação NNE-SSW a NE-SW evidenciando um aumento progressivo da deformação de oeste para leste. O presente trabalho pretende contribuir para o conhecimento da geomorfologia da cadeia da Arrábida recorrendo a técnicas de geomorfometria para a extração semiautomática e análise de formas de relevo. Dado o contexto morfotectónico, é dada particular atenção à interferência da tectónica na evolução do relevo. 


\begin{abstract}
:
This work is intended as a contribution to the knowledge of the geomorphology of the Arrábida Chain by using geomorphological and geomorphometric techniques. Given the morphotectonic context, we focus specifically on the interference of tectonic processes in relief evolution. The Arrábida Chain results from the interaction of tectonic and erosional processes acting since middle Miocene until present days. Vertical movements of the crust and sea level variations mainly controlled landscape evolution, with the drainage systems actively maintaining the dynamic equilibrium between endogenous and exogenous processes. This is expressed by the presence of perched erosional surfaces, indicating of a polycyclic evolution of the mountain chain throughout the plio-Quaternary. Superimposed to these regional processes, the vertical offset along NNE- SSW to NE -SW trending faults show a progressive increase in deformation from west to east, affecting both the northern and Southern flanks of the Chain.
\end{abstract}

\section{Introdução}

O primeiro mapa geomorfológico publicado na Europa surge há aproximadamente um século com o trabalho de Passarge (1914, in DRAMIS et al. 2011). No entanto, a cartografia geomorfológica, enquanto método de ilustração e suporte à análise de formas de relevo, terá dado os primeiros passos apenas no decorrer da década de 40/50 do século XX em virtude da publicação de mapas geomorfológicos em teses de doutoramento (ex. HELBLING, 1952; ANNAHEIM, 1956) e com o lançamento da campanha de publicação de mapas geomorfológicos na escala 1:50,000 para o território polaco (KLIMASZEWSKI, 1956 E 1963; GALON, 1962). A partir do final da década de 50 e até aos anos 90 surgiram diversos exemplos de mapas geomorfológicos, a diferentes escalas, com origem na Europa e União Soviética, sendo as legendas adaptadas aos objectivos e contexto geomorfológico das áreas de estudo (GELLERT e SCHOLZ, 1960 e 1974; TRICART, 1955, 1969, 1970 e 1972; JOLY, 1963; VERSTAPPEN e VAN ZUIDAM, 1968; VERSTAPPEN, 1970; DEMEK, 1972; PELLEGRINI et al., 1993; entre outros).

Em Portugal, sob clara influência da escola de cartografia francesa, os primeiros mapas geomorfológicos surgem no âmbito dos trabalhos de Martins (1949), Feio (1952), Ferreira (1978), Coudé-Gaussen (1981), Ferreira (1981) e Daveau et al. (1985). Surgem igualmente tentativas de sistematização metodológica e aplicativa por parte de Rebelo (1978) e, mais tarde, por Rodrigues e Zêzere (1993), Ferreira et al. (1995) e Rodrigues (2008).

Nos últimos anos assistiu-se a um desenvolvimento muito considerável das metodologias utilizadas em cartografia geomorfológica, motivado pela introdução dos sistemas de informação geográfica e de técnicas de detecção remota na análise geomorfométrica e na extra- ção automática e semi-automática de formas de relevo. A utilização de imagens de satélite de alta resolução (ex. GeoEye-1, QuickBird), de imagens multiespectrais (ex. pancromático, infravermelho) e modelos digitais do terreno (ex. LiDAR) em associação aos métodos já utilizados no passado (ex. análise estereoscópica de fotografias aéreas) permite uma leitura mais pormenorizada do território, trazendo claros benefícios em trabalhos de média a grande escala (DRAMIS et al. 2011).

A Serra da Arrábida, embora tenha sido alvo de diversos trabalhos no campo da geomorfologia, não possui, até ao momento, uma cartografia detalhada das suas formas de relevo. O primeiro trabalho de referência surge pelas mãos de Ribeiro (1936), um trabalho definido pelo autor como uma "singela contribuição para o conhecimento da Geografia Regional de Portugal". Pese embora a clareza e a atualidade do texto, este trabalho não é acompanhado por mapas, desenhos ou fotografias. Trinta e um anos mais tarde, Ribeiro (1968) elaborou um Livro-Guia de uma excursão à Arrábida, realizada no âmbito do Primeiro Seminário Internacional de Geografia, no qual divulgou a sua interpretação cartográfica da estrutura e da morfologia da Arrábida. No entanto, a cartografia apresentada pelo autor é de pequena escala e claramente adaptada à descrição dos grandes traços morfoestruturais e morfográficos da paisagem.

A geomorfologia da Arrábida foi retomada, a escalas de maior pormenor, nos trabalhos de Daveau e Azevedo (1980/81) e Alcoforado (1981), estando no entanto limitados às fachadas ocidental e oriental da Serra, respetivamente. O conhecimento da geomorfologia e geologia plio-quaternária da Península de Setúbal é reforçado com os trabalhos de Azevedo (1982) e Cabral (1993). Adicionalmente, surgiram contribuições no campo da cartografia e análise de formas e processos marinhos nos trabalhos de Pereira (1988), Pereira e 
Regnauld (1994), Regnauld et al. (1995) e Pereira et al. (2007).

Nas palavras de Orlando Ribeiro, "poucas regiões haverá onde o acordo entre as deslocações tectónicas e as formas actuais do relevo seja tão sensível" (RIBEIRO, 1936). Esta noção é expressa na totalidade dos trabalhos realizados na cadeia da Arrábida e Península de Setúbal, onde a tectónica alpina surge de modo evidente, revelando marcas de atividade Quaternária. Neste contexto, justifica-se a realização de uma cartografia de conjunto das formas de relevo, integrando as principais etapas de evolução e identificando os principais agentes morfogenéticos envolvidos. Numa publicação recente (FONSECA et al., 2014), é apresentado um mapa geomorfológico de média escala resultando da análise de fotografias aéreas, geomorfometria e levantamentos de campo.

O presente trabalho pretende contribuir para o conhecimento da geomorfologia da cadeia da Arrábida através da análise geomorfométrica do relevo. Dado o contexto morfotectónico, será dada particular atenção à interferência da tectónica na evolução do relevo. Uma versão simplificada do trabalho publicado por Fonseca et al. (2014) é aqui apresentado de forma a facilitar a leitura interpretativa do relevo. O texto que se segue justifica e complementa a informação contida no mapa geomorfológico.

\section{Quadro Geológico}

A Arrábida é uma cadeia orogénica Alpina de pequena dimensão, localizada na extremidade meridional da Orla Mesocenozóica Ocidental. É caracterizada por uma estrutura enrugada e complexa, desenvolvendo-se ao longo de aproximadamente $35 \mathrm{~km}$ segundo a orientação WSW-ENE, desde o Cabo de Espichel até Setúbal (Figuras 1 e 2). Sob um ponto de vista estrutural, é limitada a norte pelo sinclinal de Albufeira, a este pela falha de Setúbal-Pinhal Novo, a oeste por uma falha de orientação NW-SE ao largo do Cabo de Espichel (BOILLOT et al., 1978) e a sul, segundo Ribeiro et al. (1990) e Kullberg et al. (2000), pelo cavalgamento da Arrábida, situado no mar e sub-paralelo à estrutura emersa (Figuras 1 e 2). No interior do compartimento limitado pelas estruturas anteriormente referidas, destaca-se um conjunto de dobras de direção ENE-WSW, cortadas por desligamentos de direção NNW-SSE a NNE-SSW, formadas por empilhamentos de caval- gamentos vergentes para sul. As estruturas enrugadas encontram-se enraizadas num descolamento basal ao nível do contacto entre as unidades da bacia sedimentar mesocenozóica, materializado pelo complexo evaporítico do Hetangiano (margas da Dagorda), e o soco paleozóico (KULLBERG et al., 2000).

Neste contexto, encontram-se formações sedimentares do Jurássico ao Miocénico, filões eruptivos e depósitos discordantes de idade plio-quaternária (Figura 1). A sedimentação mesozóica evoluiu inicialmente em regime distensivo, segundo uma orientação W-E, desde o Triásico ao Cretácico superior, em resposta às primeiras fases de rifting do oceano Atlântico. No Cenozóico é instaurado um regime compressivo derivado da colisão entre as placas Africana e Euroasiática, levando à formação de dobras e cavalgamentos a partir da reativação inversa de falhas normais, ativas durante o Mesozóico (RIBEIRO et al., 1990).

O sector ocidental da Arrábida é o menos invertido de toda a cadeia, destacando-se a estrutura monoclinal do Cabo de Espichel, flanco norte de uma dobra com eixo no mar ( $1^{\mathrm{a}}$ linha de deslocamento de Choffat, 1908) e as estruturas diapíricas da Cova da Mijona e Sesimbra (KULLBERG et al., 2000). A oriente, a estrutura é mais complexa, caracterizando-se por um conjunto de dobras com eixo WSW-ENE a E-W, associadas a rampas de cavalgamentos imbricados de direcção ENE-WSW vergentes para $\mathrm{S}$, conectadas por rampas laterais esquerdas oblíquas aos cavalgamentos de direção NNE-SSW a N-S (KULLBERG et al., 2000; KULLBERG et al., 2006). Destacam-se, neste sector, os anticlinais do Formosinho e do Viso - $2^{\mathrm{a}}$ linha de deslocamento - e de S. Luís - $3^{\mathrm{a}}$ linha de deslocamento - (CHOFFAT, 1908).

A série sedimentar mesozóica tem início com as margas do complexo evaporítico da Dagorda (Triásico superior - Hetangiano), sendo a transição para as unidades sobrejacentes marcada por uma alternância de rochas eruptivas de natureza oolítica, de tufos vulcânicos argilosos e pelitos com gesso e dolomitos (MANUPPELLA et al., 1999). A unidade sedimentar da Dagorda desempenhou um papel fundamental na evolução da estrutura da cadeia da Arrábida, e em particular do diapiro de Sesimbra, favorecendo o descolamento e rutura da cobertura meso-cenozóica ao longo do cavalgamento da Arrábida entre o final do Cretácico e o Paleogénico e no decorrer da inversão tectónica miocénica (RIBEIRO et al., 1990). 


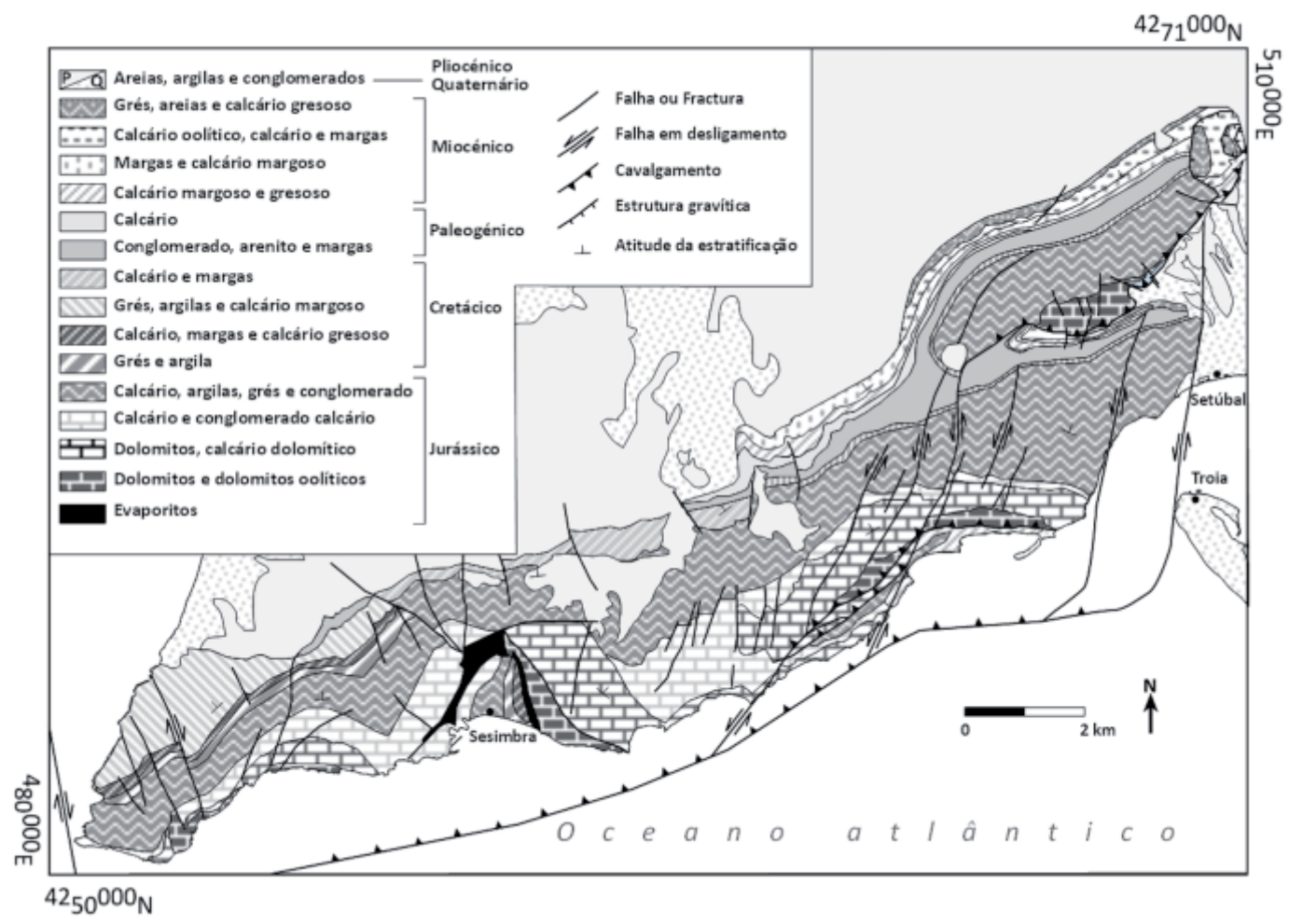

Figura 1 - Mapa geológico simplificado da cadeia da Arrábida, adaptado de Manupella et al. (1999) e Kullberg et al. (2000).

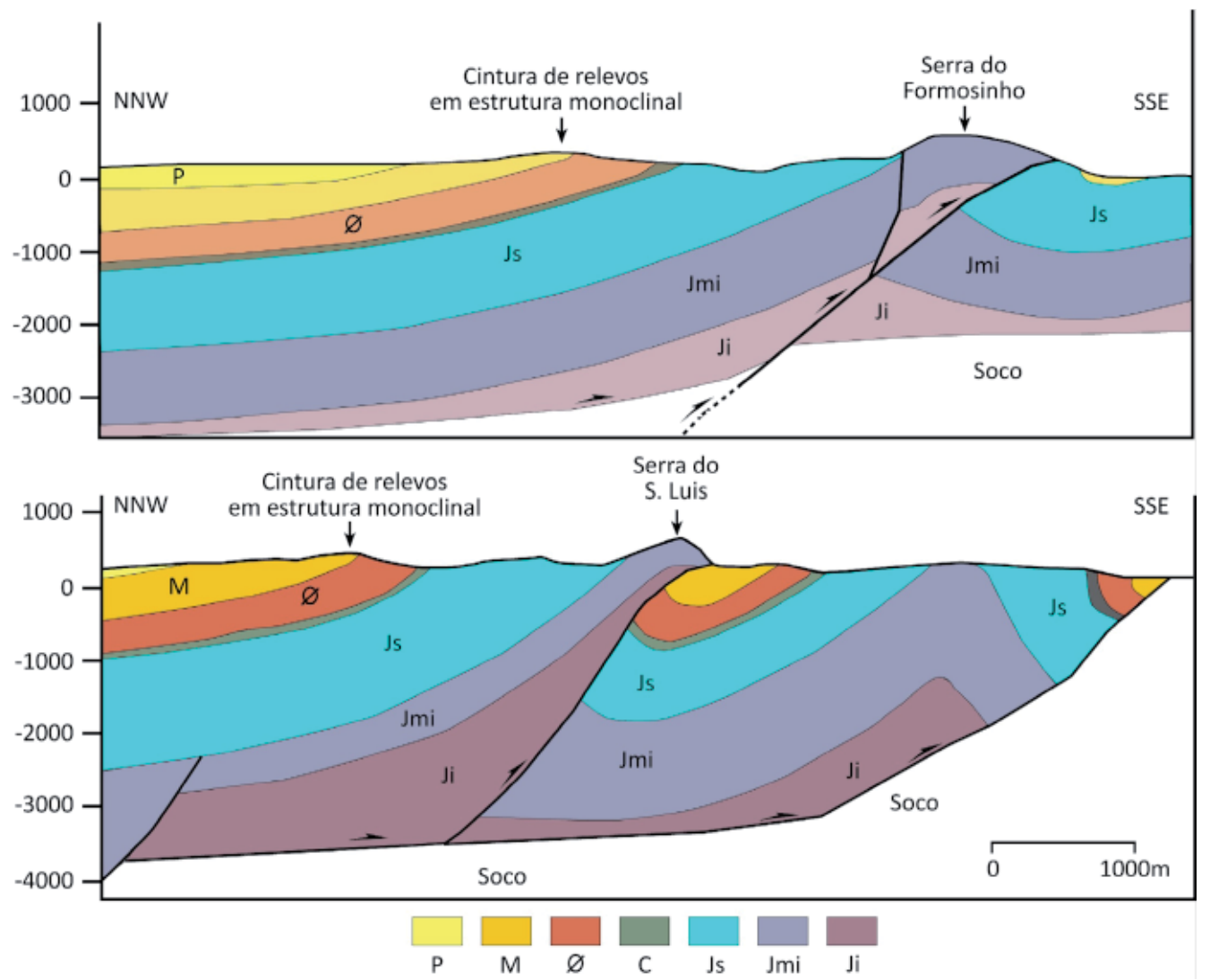

Figura 2 - Cortes geológicos simplificados. Adaptado de Kullberg et al., (2000). P) Pliocénico; M) Miocénico; ๑)Paleogénico; C) Cretácico; Js) Jurássico superior; Jmi) Jurássico médio-inferior; Ji) Jurássico inferior. 
O Jurássico inferior a médio é dominado por rochas carbonatadas (dolomitos, calcários dolomíticos, margas dolomíticas), depositadas em ambiente marinho pouco profundo, alternando com intercalações margosas, argilosas e de calcário lacustre, referentes a breves etapas de aprofundamento da bacia. Para o topo da sequência jurássica, as variações laterais de fácies são bastante acentuadas, traduzindo-se no afloramento de bancadas de calcário compacto de cor clara com intercalações margosas entre o sector ocidental da Ribeira da Pateira e o Cabo de Espichel e de sedimentos argilo-arenosos, conglomeráticos e gresosos, pouco consolidados, ao longo dos vales das ribeiras de Coina, Ajuda, Alcube e Corva (MANUPPELLA et al., 1999). Estas observações sugerem que o território hoje ocupado pela cadeia da Arrábida seria, no decorrer do Jurássico superior, caracterizado por um ambiente de sedimentação de transição marinho-litoral.

A tendência de subsidência prolonga-se pelo Cretácico com a sedimentação de calcários, margas e grés. A entrada na era cenozóica é assinalada pelo rejuvenescimento do relevo em resposta ao início da compressão Alpina e pela deposição de conglomerados calcários e arenitos grosseiros de idade paleogénica, seguido por calcários com nódulos e rizoconcreções com sinais evidentes de pedogénese (MANUPPELLA et al., 1999). A presença de litofácies grosseiras de natureza calcária nos sedimentos paleogénicos implica já uma exposição sub-aérea, ainda que parcial, da ossatura calcária jurássica, anteriormente à inversão tectónica do Miocénico.

Durante o Miocénico, a península de Setúbal é invadida pelas águas do Atlântico, resultando na formação de calcários, calcários margosos e gresosos que constituem os relevos em estrutura monoclinal ao longo do limite norte da Serra (Pré-Arrábida) e que marcam a transição entre a unidade meso-cenozóica e os sedimentos plio-quaternários do Sinclinal de Albufeira. A sedimentação miocénica termina com os depósitos continentais do Conglomerado de Guarda Mor de idade Tortoniana e com os depósitos marinhos da Ribeira da Laje, de idade incerta entre o Tortoniano e o Messiniano (MANUPPELLA et al., 1999).

Sobre o Miocénico assenta a série detrítica arenosa grosseira atribuída ao Pliocénico inferior, depositada em regime de subsidência pelo organismo fluvial do pré Tejo (AZEVEDO, 1982). O contacto entre as formações miocénicas e pliocénicas é efetuado por uma superfície de desconformidade nítida, correspondendo, a sul da
Lagoa de Albufeira, a uma paleotopografia de relevo pronunciado, preenchida por depósitos cascalhentos - a Série inferior do Alfeite (CABRAL et al., 1984; CABRAL, 1993). A discordância sedimentar poderá ter origem tectónica, em resposta ao segundo impulso tectónico da cadeia da Arrábida (8M.a.), ou eustática, na sequência da maior inflexão negativa da curva eustática durante o Tortoniano inferior (MANUPPELLA et al., 1999). A norte da serra de S. Francisco, Azevedo (1982) refere a presença de depósitos grosseiros (Formação de Cabanas), resultantes de descargas torrenciais a partir do anticlinal de S. Luís para o interior da Península de Setúbal. De acordo com Manupella et al. (1999), esta série conglomerática poderá ser correlativa da série inferior do Alfeite, assumindo assim uma idade fini-Miocénica.

A série sedimentar pliocénica, constituindo uma unidade sintectónica da deformação e enchimento aluvial do Sinclinal de Albufeira, apresenta-se como uma megasequência com características extremamente variáveis que impossibilitam a definição de uma sequência estratigráfica precisa (AZEVEDO, 1982). De acordo com Manuppella et al. (1999), a base da formação é caracterizada por conglomerados pouco espessos, seguindo-se areias finas a grosseiras com estratificação entrecruzada, com cor variável desde o branco, ao amarelo e vermelho. No seio das areias ocorrem blocos de arenito cretácico e nódulos de sílex.

$\mathrm{Na}$ cartografia geológica de Zbyszewski et al. (1965), Azevedo (1982) e Manuppella et al. (1999), os depósitos pliocénicos estendem-se de norte para sul até ao rebordo setentrional da Cadeia da Arrábida, sendo inclusivamente identificadas algumas manchas no interior do maciço, ao longo dos vales centro-orientais, assentando em discordância sobre o Paleogénico e o Jurássico superior, a uma altitude média de 116 metros (max. 154m; min. 74m). No entanto, de acordo com Alcoforado (1981) e Azevedo (1982), a sua distribuição é muito superior, cobrindo retalhos aplanados em torno dos 100 metros de altitude a sul da serra de S. Luís.

Estas observações levam a supor que o limite sul do pré-Tejo ter-se-á estendido mais para sul, cobrindo parcialmente o sector setentrional da Arrábida. No entanto, residem diversos problemas quanto à idade absoluta e proveniência dos sedimentos aí encontrados. Segundo Alcoforado (1981) e Azevedo (1982), algumas das manchas ditas pliocénicas, sobretudo aquelas situadas ao longo dos flancos da ribeira da Ajuda e a sul do S. Luís, são caracterizadas por depósitos arenosos e pouco 
argilosos, apresentando evidências de remobilização eólica. As frações arenosas mais finas apresentam uma forte afinidade com os sedimentos que caracterizam as areias pliocénicas (AZEVEDO, 1982).

De acordo com Manuppella et al. (1999), a evolução quaternária da região da Península de Setúbal é caracterizada pela passagem de uma longa fase de sedimentogénese em regime de subsidência durante o Pliocénico, para uma fase de gliptogénese no Quaternário, com erosão e encaixe da rede hidrográfica em resposta a um levantamento de conjunto de quase toda a região.

À sequência arenosa pliocénica sobrepõe-se o Conglomerado de Belverde (Pliocénico superiorQuaternário inferior), formação fluvial depositada pelo pré-Tejo e posteriormente remobilizada pelo mar no decorrer da transgressão calabriana (AZEVEDO, 1982). A sua sedimentação ocorre durante o período que antecede a inflexão do Tejo para oeste com estabelecimento ao longo da linha de fraqueza estrutural do gargalo do Tejo (AZEVEDO, 1982). Segundo esta autora, os depósitos referentes a esta fase de agradação encontram-se preservados a norte e sul da Lagoa de Albufeira, contendo calhaus rolados de quartzito, quartzo filoniano e de rochas eruptivas provenientes do Complexo Vulcânico de Lisboa. A inclinação para nordeste da superfície basal do conglomerado de Belverde é indicativa de que o movimento de subsidência do Sinclinal de Albufeira perdurou durante grande parte do período plio-quaternário, a uma taxa aproximada de $4 \mathrm{~mm} /$ século (AZEVEDO, 1982).

Em associação a um clima sub-árido formam-se os depósitos de origem torrencial da Formação de Marco Furado (Quaternário inferior) por desmantelamento dos relevos talhados nas formações miocénicas e cretácicas que limitam o bordo setentrional da cadeia da Arrábida. Estes assentam por uma superfície erosiva sobre as areias pliocénicas e sobre o conglomerado de Belverde, ocupando uma vasta área em torno da cadeia, até uma altitude máxima de 100-110 metros. De acordo com Azevedo (1982), os depósitos são constituídos por uma matriz areno-argilosa de cor avermelhada e por uma fracção grosseira constituída por quartzo filoniano, anguloso a sub-rolado, com dimensões compreendidas entre 0,5 e $20 \mathrm{~cm}$ e por quartzito, jaspe, xisto e sílex. Os materiais mais finos resultam da remobilização da Formação de Cabanas e dos sedimentos pliocénicos. Os materiais grosseiros provêm da erosão das camadas do Jurássico superior e Cretácico e da remobilização dos materiais mais grosseiros da Formação de Cabanas. Estes depósitos são caracterizados ainda pela total ausência de calcário, facto que Azevedo (1982) considera difícil de explicar. Embora considere a possibilidade de este material ter sofrido dissolução, não são no entanto encontradas quaisquer evidências de horizontes de dissolução, quer na base quer no topo da formação pliocénica no qual este assenta (AZEVEDO, 1982).

Em épocas mais recentes do Quaternário (Wurm) formam-se acumulações dunares que se estendem até próximo de Quinta do Anjo e Palmela (AZEVEDO, 1982), bem como os campos de dunas ao longo da costa ocidental, de idade holocénica, que chegam a atingir um desenvolvimento vertical de 60 metros (Manuppella et al., 1999).

\section{Metodologia}

O mapa geomorfológico que acompanha o presente trabalho procura expressar cartograficamente o estado da arte no campo da geomorfologia da Serra da Arrábida, complementando a informação existente com a análise de fotografias aéreas e análise geomorfométrica do relevo. A sua elaboração contemplou três fases: 1) leitura bibliográfica, digitalização de mapas geomorfológicos e geológicos (ZBYSZEWSKI et al. 1965; DAVEAU e AZEVEDO, 1980-81; ALCOFORADO, 1981; CABRAL, 1993; PEREIRA e REGNAULD (1994); MANUPELLA et al., 1999; KULLBERG et al. 2000); 2) interpretação estereográfica de fotografias aéreas, análise de imagens aéreas orto-retificadas e análise e interpretação do relevo com recurso a software SIG; 3) produção do mapa final.

Depois do trabalho pioneiro de Orlando Ribeiro, surgiram nas décadas de 80 e 90 do século XX contribuições relevantes no campo da cartografia geomorfológica da Arrábida (DAVEAU e AZEVEDO, 1980-81; ALCOFORADO, 1981; PEREIRA e REGNAULD, 1994). No entanto, por razões de escala e consistência cartográfica do mapa final, os trabalhos acima citados, após digitalização e georreferenciação, apenas foram utilizados no auxílio de definição da tipologia das formas de relevo, não sendo efetuada qualquer vectorização a partir destes. Toda a vectorização foi executada a partir de fotografias aéreas (voo FAP n॰9, escala 1:25,000 de 1967) e ortofotomapas (IGP 2007, resolução 0,5m RGB. Folhas 453,454, 464 e 465). Face à elevada densidade de informação a representar e à 
pequena escala do mapa final $(\approx 1: 100,000)$, optou-se pela não inclusão de informação referente à litologia na medida em que dificultaria a leitura do mapa e não resultaria num contributo relevante face ao trabalho publicado por Manupella et al. (1999). A informação referente à tectónica foi extraída de Manupella et al. (1999), de Kullberg et al. (2000) e da análise de fotografias aéreas.

As técnicas de geomorfometria foram utilizadas com o objectivo de complementar a informação já publicada, validar algumas das observações efectuadas no decorrer da foto-interpretação e compreender em que medida as deformações tectónicas quaternárias interferiram na evolução do relevo da cadeia da Arrábida. O estudo baseou-se na extração e análise de dados com recurso a software SIG a partir de um modelo digital do terreno (MDT) com pixel de $10 \mathrm{~m}$, criado com base na informação topográfica digital referente à cartografia militar na escala de 1:25,000.

A interferência da tectónica foi avaliada, em primeira linha, a partir da análise da altitude máxima calculada através de estatística de vizinhança numa matriz de 100x100 pixels $\left(1 \mathrm{~km}^{2}\right)$ e do mapa de nível de base (Base Level Map) criado a partir da interpolação de valores de altitude atribuídos aos segmentos de drenagem. Os mapas de altitude máxima permitem avaliar, de forma aproximada, a topografia pré-degradação, sem a interferência de valores mínimos resultantes da sua erosão. O mapa de nível de base corresponde à superfície de menor altitude, estabelecendo ligação entre fundos de vale, sendo representativa do grau de encaixe da rede de drenagem. Foi igualmente calculada a diferença entre a altitude máxima e mínima, de forma a analisar a amplitude altimétrica do relevo e avaliar a variação espacial do grau de entalhe a partir da degradação da superfície de altitude máxima. A análise dos valores obtidos permite inferir o comportamento da topografia ao longo de perfis transversais e examinar o papel das estruturas tectónicas previamente identificadas na deformação da superfície topográfica herdada e actual.

A cadeia da Arrábida é limitada a norte por uma cintura de relevos em estrutura monoclinal, estabelecendo a fronteira entre o domínio tectónico de levantamento da Arrábida e o domínio de subsidência do Sinclinal de Albufeira. Ao longo da sua extensão W-E, estes relevos são dissecados pela rede de drenagem proveniente dos sectores mais elevados da Serra segundo a direção SSE-NNW a S-N. Dado o contexto geomorfológico, pareceu-nos relevante analisar estatisticamente a relação entre as seguintes variáveis morfométricas, que se relacionam com o encaixe da rede hidrográfica, de modo a compreender de que modo se processa a sua variação espacial (Figura 3): (i) área de drenagem a montante dos sectores entalhados; (ii) relevo da área de drenagem a montante dos sectores entalhados; (iii) comprimento máximo de drenagem; (iv) amplitude de entalhe do relevo monoclinal.

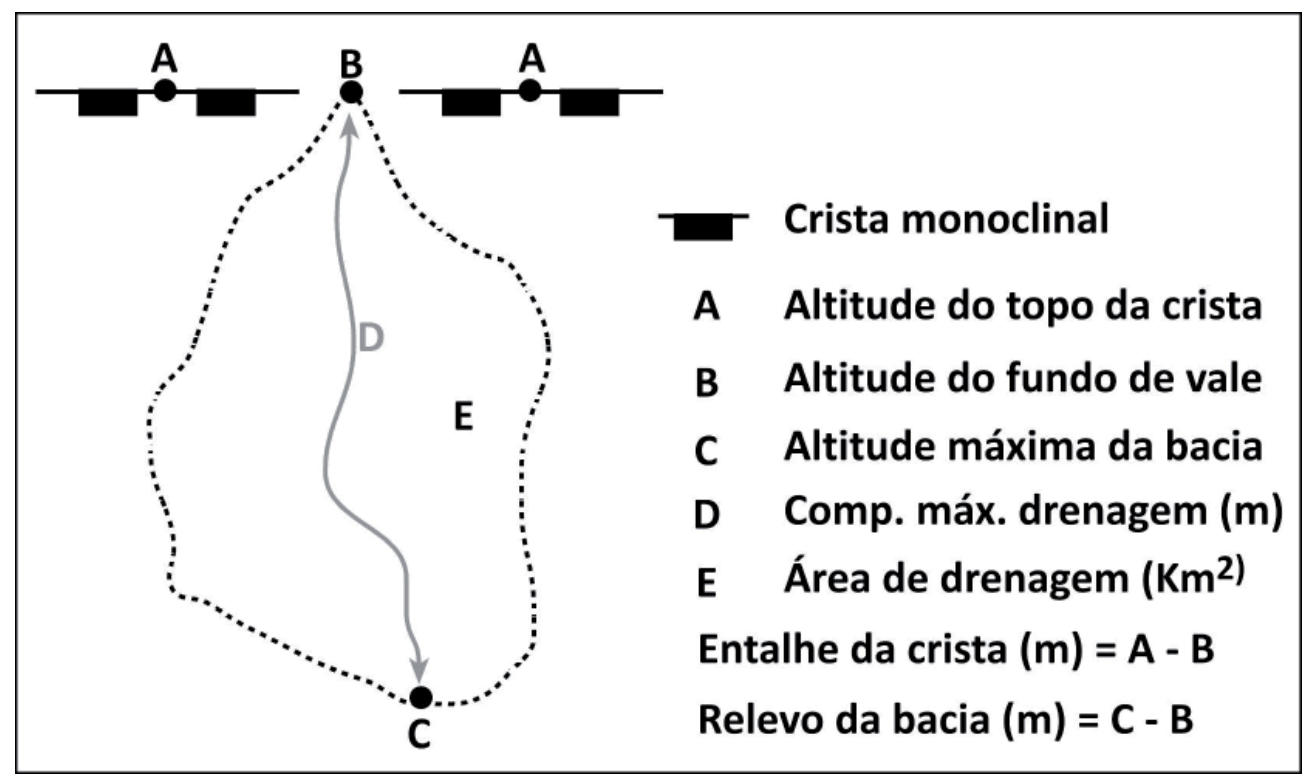

Figura 3 - Esquema de caracterização dos parâmetros morfométricos utilizados na análise do grau de entalhe da cintura de relevos em estrutura monoclinal. 
Uma das principais dificuldades do presente trabalho prende-se com a comparação dos dados existentes acerca da evolução do relevo nos sectores oriental e ocidental da Arrábida, nomeadamente no que se refere aos diferentes níveis de aplanamento identificados por Daveau e Azevedo (1981) e Alcoforado (1981). Foi assim necessário procurar compreender se o escalonamento altitudinal dos diferentes níveis descritos na bibliografia seria comparável, sobretudo para o sector central do maciço para o qual não existem dados. A utilização do modelo digital do terreno permitiu a extração automática dos diferentes níveis aplanados, recorrendo a uma função condicional aplicada ao mapa de declives (em graus, não classificado), isolando vertentes de declive igual ou inferior a 2 graus de acordo com a metodologia proposta por Calvet e Gunnell (2008). Ao mapa obtido foi aplicada uma máscara eliminando os sectores de fundo de vale plano, sendo posteriormente reclassificado de acordo com uma função booleana (Declive $=1, ?=$ 0 ), permitindo assim o cruzamento com o MDT classificado de 10 em 10 metros. A análise de histogramas de frequência (Figura 4) possibilitou compreender de que modo se processa o escalonamento altitudinal das formas de relevo aplanadas e isolar situações anómalas resultantes da sua deformação.
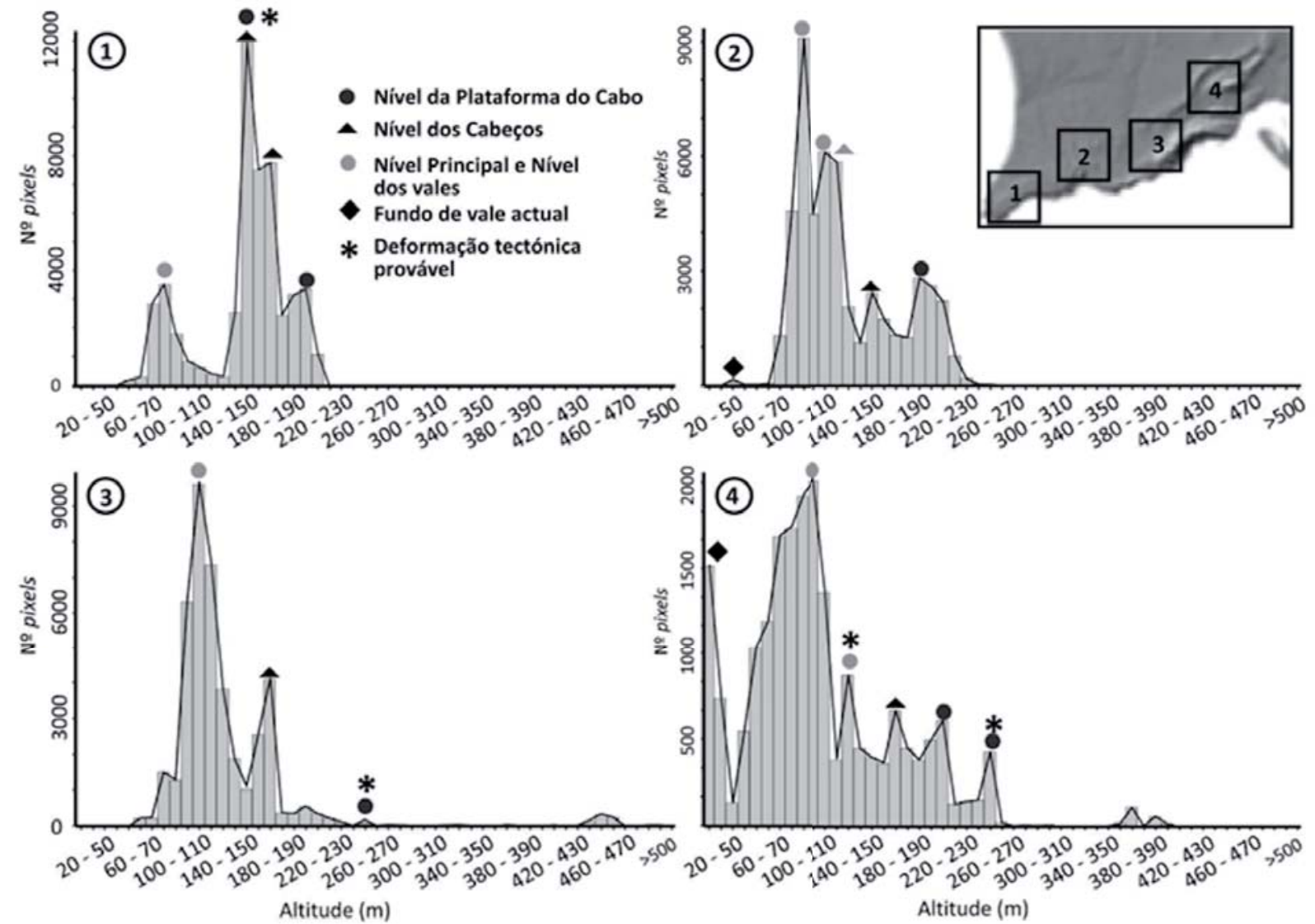

Figura 4 - Histogramas de frequência de vertentes com declive inferior ou igual a 2 graus por classe de altitude (10 metros) e relação com os niveis de aplanamento identificados no mapa geomorfológico para 4 áreas amostra (1pixel =100m2; áreas amostra correspondem a quadrículas de $5 \times 5 \mathrm{~km})$.

Com o intuito de compreender em que medida o controlo estrutural se materializa na morfologia recorreu-se a parâmetros morfométricos utilizados na análise de bacias hidrográficas (Figura 5): I) Curva hipsométrica (STRAHLER, 1952); II) ICA - Índice de Comprimento - Área (CHRISTOFOLETTI, 1980); III)
IA - Índice de Assimetria de bacia (KELLER e PINTER, 2002); IV) RER - Rácio de Elevação-Relevo (PIKE and WILSON, 1971); V) D - Declive médio. Estes foram aplicados a 14 bacias hidrográficas geradas automaticamente a partir do modelo digital do terreno. Não foram selecionadas bacias no troço compreendido entre 
o Cabo de Espichel e a ribeira da Ajuda $\left(n^{\circ} 11\right)$ por se enquadrarem no contexto da vertente costeira. O limite jusante das bacias estudadas é o mar para as bacias 1 a 6 e 11 a 14 e a Lagoa de Albufeira para as bacias 7 a 9. Por uma questão de escala de análise colocou-se o limite jusante da bacia $\mathrm{n}^{\mathrm{o}} 10$ (Rib. de Coina) no alinhamento das bacias 7 a 9, correspondente à posição aproximada do eixo do Sinclinal de Albufeira (Figura 5A).

A rede de drenagem foi gerada automaticamente a partir do MDT, utilizando um limiar de acumulação de fluxo (D8 FlowAccumulation model) de 250 pixels, por resultar (por comparação visual) numa maior proximidade ao padrão de drenagem representado na carta topográfica na escala de 1:25,000. O controlo estrutural foi analisado a partir da comparação de diagramas de orientação calculados para os segmentos de drenagem, para os rele- vos estruturais e falhas identificadas na carta geológica 1:50,000 (MANUPPELLA et al., 1999) (Figura 5B).

Para alguns dos índices calculados (ex. ICA e IA) foi necessária a identificação do canal de drenagem principal, tendo este sido definido como o segmento de drenagem mais longo e, simultaneamente, com maior grau de entalhe (em teoria, o mais antigo e/ou ativo). A extração do segmento de drenagem mais longo (DL) resultou de um processo automático. Já o grau de entalhe $(\mathrm{Ge})$ envolveu a hierarquização prévia da rede de drenagem segundo o método de Strahler e a extração automática das cumeadas laterais para segmentos de ordem superior ou igual a 2. Os segmentos de drenagem e os segmentos resultantes da operação anterior foram convertidos para um mapa de pontos (1 ponto por cada segmento, localizado na secção intermédia de cada ve-

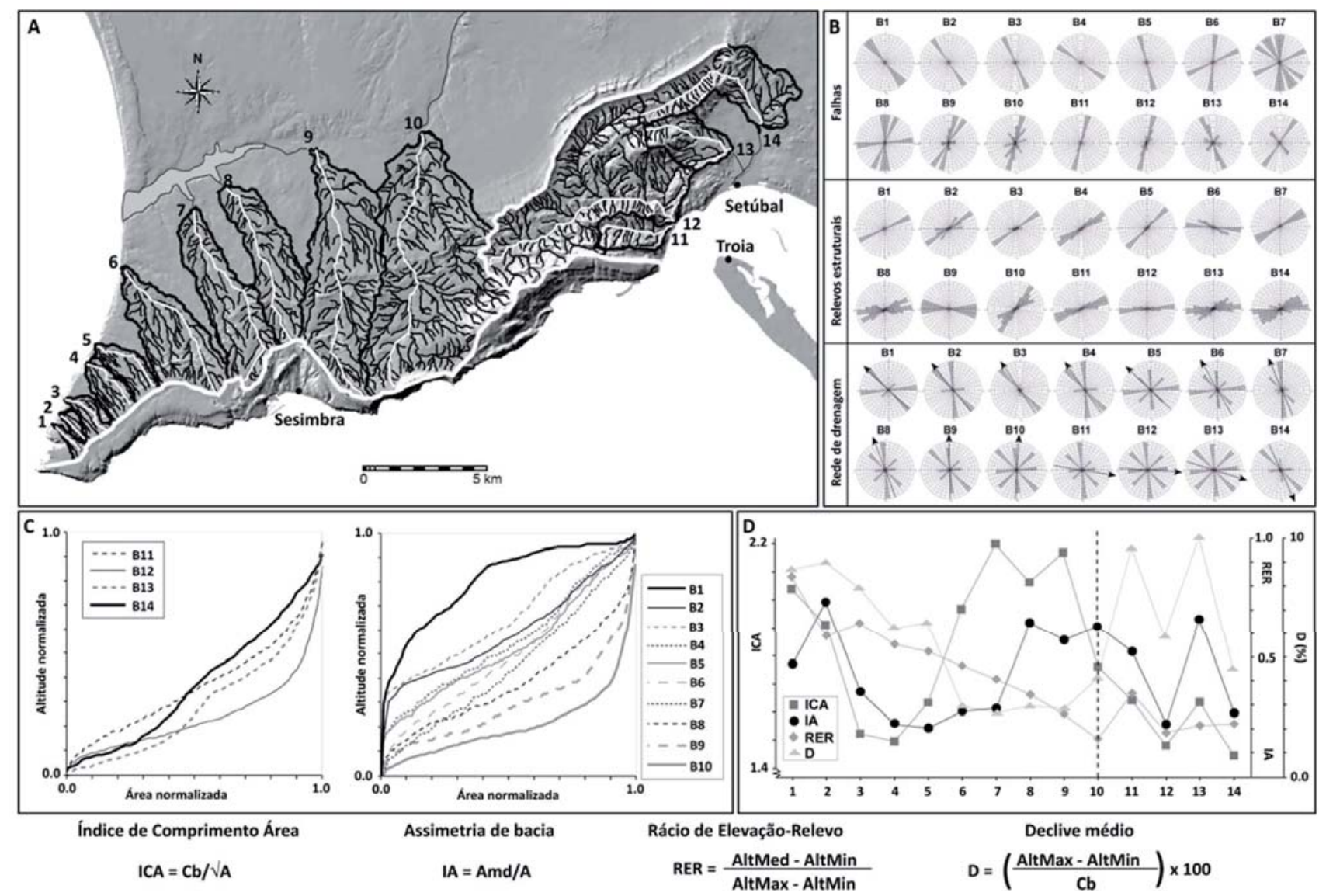

Figura 5 - Morfoestrutura e morfometria das bacias hidrográficas. A) Limite das 14 bacias analisadas. O traço branco (largo) identifica as principais linhas divisórias de água; o traço a branco (fino) identifica o posicionamento do canal de drenagem principal, utilizado no cálculo dos parâmetros morfométricos. B) Diagramas de orientação de falhas, relevos estruturais e rede de drenagem. Seta a preto identifica a direção de desenvolvimento de cada bacia. C) Curvas hipsométricas normalizadas (Bacias cataclinais de 1 a 10; Bacias ortoclinais de 11 a 14). D) Relação entre parâmetros morfométricos. ICA - Índice de Comprimento-Área (Christofoletti, 1980) (Cb=Comprimento máximo da bacia; A=Área da bacia); IA - Índice de Assimetria (Amd = Área da margem direita); RER-Rácio de Elevação-Relevo; D-Declive médio (\%). 
tor) sendo atribuído o mesmo identificador (ID) a cada sequência de 3 pontos em posição transversal ao canal de drenagem. Foram extraídos os valores de altitude para cada ponto e calculadas as diferenças entre os valores mais elevados, correspondentes à cumeada lateral e os valores mais baixos correspondentes ao talvegue. $\mathrm{O}$ valor final foi atribuído ao ponto central (talvegue) e, posteriormente, ao respetivo segmento de drenagem. Este procedimento permitiu confirmar se o resultado da operação automática para a extração de DL favorecia o critério previamente definido. Os desvios ( $\mathrm{DL} \neq \mathrm{Ge}$ ) apenas ocorreram no sector oriental (bacias 1 a 3), em virtude da menor hierarquização da rede de drenagem.

A última fase do processo de cartografia consistiu na elaboração do mapa final, procurando expressar os resultados obtidos no decorrer da foto-interpretação e análise geomorfométrica do relevo. A legenda utilizada está organizada segundo grupos morfogenéticos e a simbologia adoptada, embora em monocromático, segue, em parte, o trabalhos de Tricart (1972) e Pellegrini et al. (1993). Os diferentes níveis de informação vetorizados em ambiente SIG foram exportados em formato Dxf (Drawing Exchange Format), importados para um software de design gráfico e transformados de acordo com a legenda adoptada. Devido ao grau de pormenor do levantamento efetuado com base nas fotografias aéreas, foi necessária a generalização cartográfica de alguns aspetos do relevo, nomeadamente no que se refere aos relevos estruturais, formas de origem fluvial e contorno de níveis aplanados. De modo a realçar o contraste morfológicos entre as áreas aplanadas a oeste, a depressão de Sesimbra e os relevos positivos do Formosinho, S. Luís, Alto da Madalena e S. Francisco, optou-se pela colocação de uma imagem de relevo sombreado no fundo do mapa, sobrepondo a esta uma rede de pontos cotados extraídos das cartas militares de Portugal na escala de 1:25,000 da região de Setúbal (Série M888 - folhas 453, 454, 464 e 465).

\section{O Relevo da Cadeia da Arrábida}

A cadeia da Arrábida resulta da interação de processos tectónicos e erosivos ao longo de um período de tempo alargado, situado entre o Miocénico médio e a atualidade. $\mathrm{O}$ desmantelamento da cadeia processou-se em função da componente de movimentação tectónica e da posição da linha de costa, desempenhando a rede hidrográfica um papel fundamental no restabelecimento do equilíbrio dinâmico entre processos endógenos e exógenos. Esta relação está expressa no escalonamento altitudinal de formas erosivas aplanadas e suspensas sobre a rede de drenagem atual, evidenciando uma evolução policíclica do relevo controlada pelo levantamento da Serra da Arrábida, pela subsidência do Sinclinal de Albufeira e pelas oscilações do nível do mar no decorrer do período plio-quaternário.

Em traços gerais, é possível compartimentar o relevo da cadeia da Arrábida em três unidades morfológicas, em função de uma fronteira altimétrica situada entre os 190 e os 220 metros de altitude: acima dos 220 metros encontram-se os relevos positivos das Serras do Formosinho e S. Luís (Figura 6A) e os relevos do Cabo de Ares e Píncaro; entre os 190 e os 220 metros desenvolve-se uma superfície de abrasão marinha, genericamente denominada de Nível da Plataforma do Cabo (Figura 6B); abaixo dos 190 metros encontra-se a cintura de relevos em estrutura monoclinal, os vales centro-orientais e a depressão periférica, a depressão de Sesimbra e as rechãs litorais. Esta subdivisão altimétrica está intrinsecamente ligada, como se verá, com a cronologia evolutiva do relevo, sendo por esse motivo aqui adotada.

\subsection{As Serras do Formosinho e de S. Luís}

Acima dos 220 metros de altitude destacam-se os relevos estruturais da serra do Formosinho e serra de S. Luís, talhados nos dolomitos e calcários dolomíticos do Jurássico inferior. Estes são coincidentes com o eixo de dobras anticlinais de orientação ENE-WSW, limitadas a sul por escarpas de falha vigorosas em associação a planos de cavalgamento inclinados para norte. Estas serras apresentam características de Montes Anticlinais (mont), típicos do relevo jurassiano.

A serra do Formosinho constitui uma dobra anticlinal dissimétrica de traçado curvo, desenvolvendose segundo as orientações ENE-WSW (entre El Carmen (439m) e o Formosinho (501m)) e E-W (entre o Formosinho e a Arremula (347m)) (Figura 7). O topo da serra é caracterizado por uma superfície pouco acidentada, desenvolvendo-se entre 340 e 500 metros de altitude. No entanto, constata-se que os principais ressaltos altimétricos são coincidentes com uma rede de acidentes de orientação NNE-SSW a NE-SW e NW-SE (Figura 7). Para sul, as altitudes decrescem bruscamente até ao mar por uma vertente declivosa de 


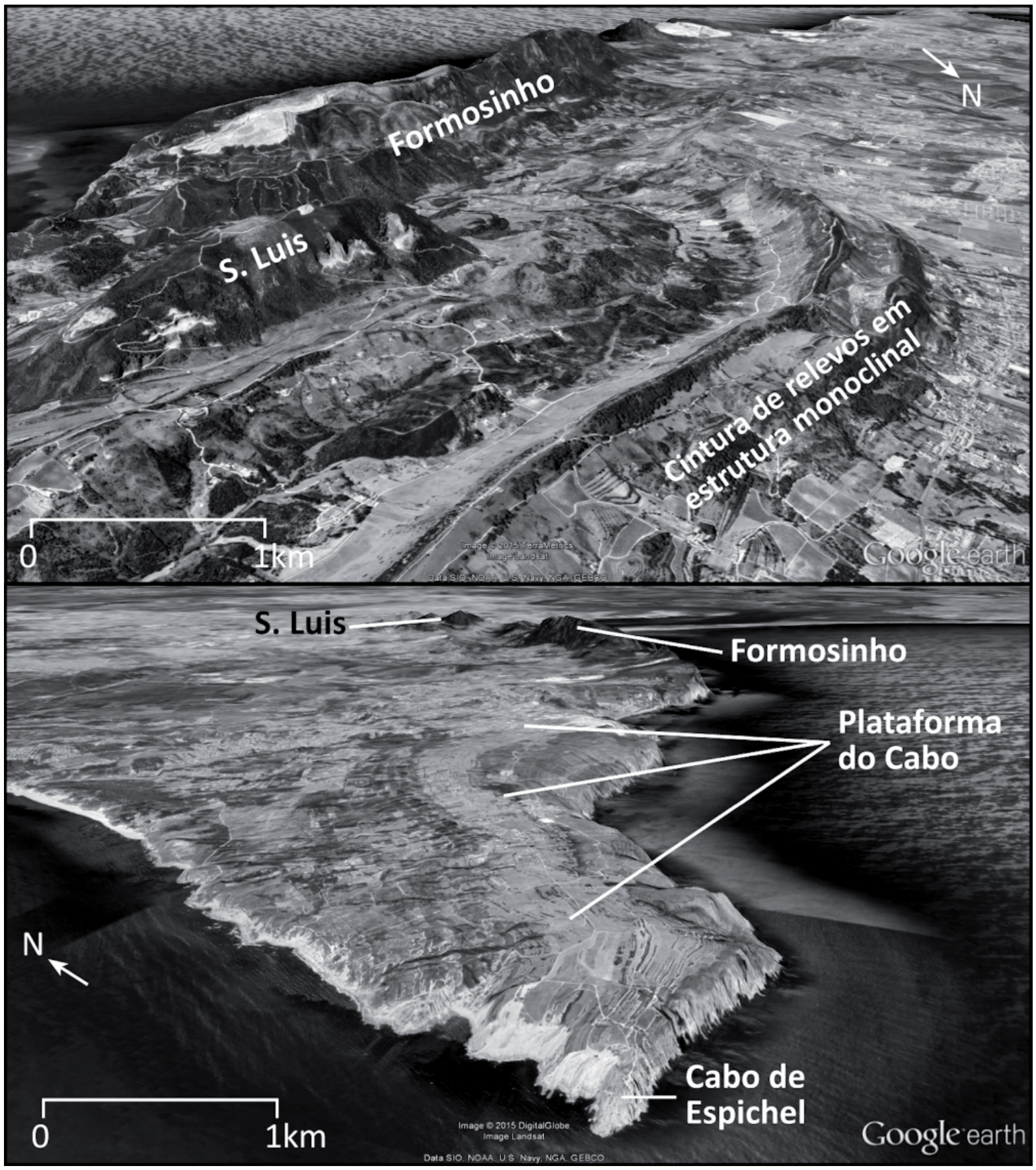

Figura 6 - Visão birds-eye view da cadeia da Arrábida indicando os principais elementos da sua morfologia. Imagens extraídas da aplicação Google Earth.

traçado coincidente com o cavalgamento da Arrábida. A fase de deformação tectónica paroxismal responsável pelo levantamento da Serra terá ocorrido entre 17,5 e os 16,5 Ma (KULLBERG et al., 2006).

Ao longo da vertente norte da serra do Formosinho individualizam-se relevos em hogback e em chevron por erosão diferencial das camadas mais brandas do Jurássico superior (Figura 7), encontrando-se as vertentes atapetadas por depósitos cascalhentos, resultantes da degradação das vertentes calcárias amplamente fraturadas. O entalhe da rede hidrográfica delineia neste sector um sistema de vales e valeiros de orientação NW-SE a WNW-ESE, que constituem os afluentes mais elevados das ribeiras de Coina, Alambre e Ajuda. Estes tendem a ser mais encaixados no sector centro-norte, ao longo do troço de disposição E-W do anticlinal do Formosi- 
nho, explorando as margas, argilas e conglomerados do Jurássico superior.

A sudoeste de El Carmen, a altitude diminui bruscamente por uma sequência de degraus aplanados em torno dos 250 metros (Figura 7), até atingir a superfície da Plataforma do Cabo a 200-220 metros, que circunda neste local os relevos do Píncaro (380m) e serra de Ares $(310 \mathrm{~m})$. Entre o Formosinho e o Píncaro desenvolve-se uma depressão flúvio-cársica alongada segundo a orientação E-W (Terras do Risco e Fojo), preenchida por sedimentos finos argilo-arenosos. O fundo desta depressão situa-se em torno dos 160-170 metros (Figura 7).

Para nordeste do Formosinho encontramos a serra de S. Luís (392m), constituída por calcários dolomíticos do Jurássico inferior e médio. Com uma orientação W-E a WSW-ENE, prolonga-se até Palmela pela Serra dos Gaiteiros, acompanhando o traçado de uma falha em cavalgamento que a limita pelo flanco sul. Tal como o Formosinho, esta forma uma dobra assimétrica de orientação WSW-ENE, fragmentada por uma rede de falhas de orientação submeridiana e cavalgante para sul sobre o Miocénico, deformando-o em sinclinal (sinclinal do Zimbral). O topo da Serra desenvolve-se em torno dos 340-390 metros, diminuindo para ENE por uma sequência de degraus entre os 280-320 metros até atingir o topo aplanado da serra dos Gaiteiros a uma altitude de 200-220 metros.

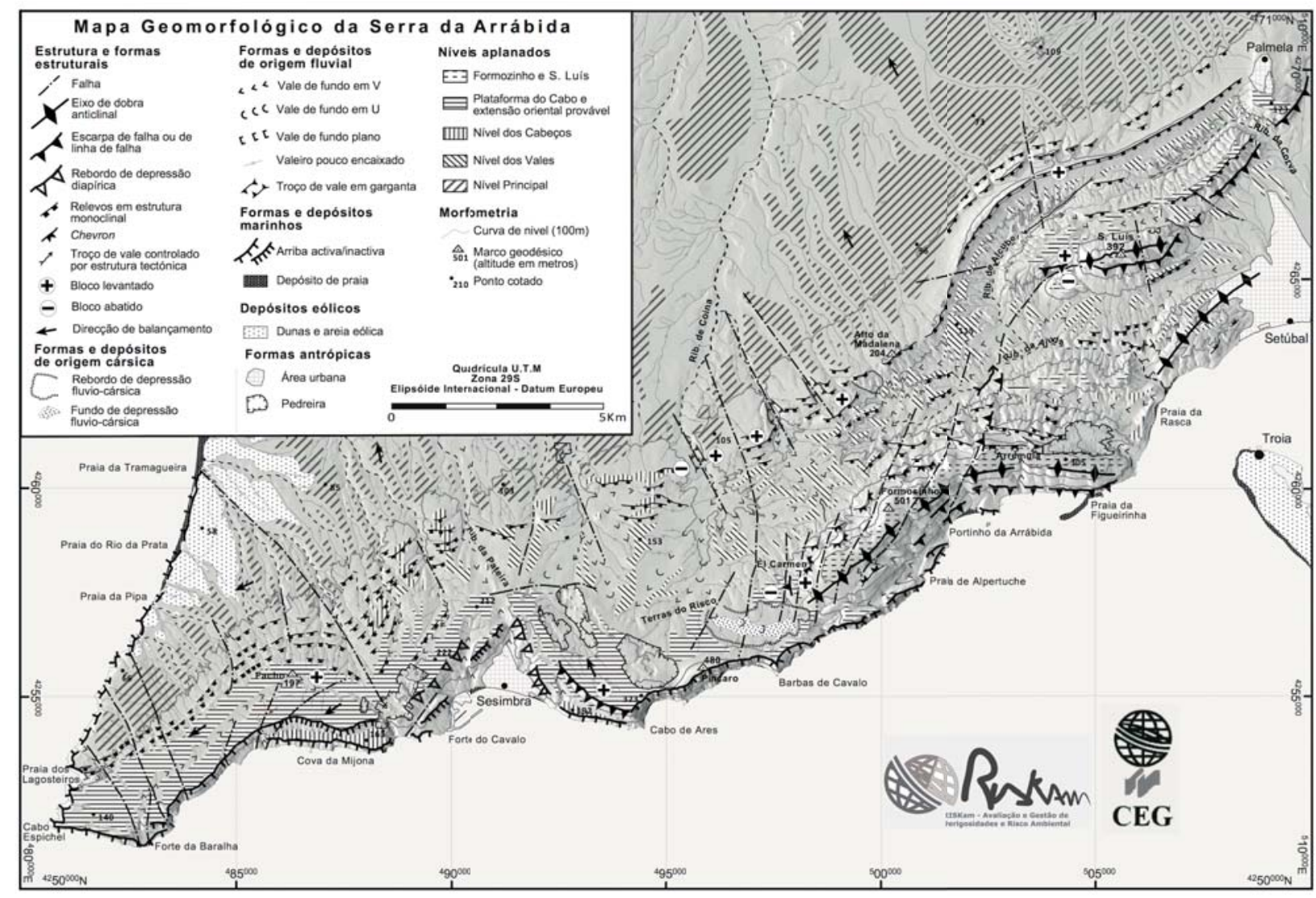

Figura 7 - Mapa geomorfológico simplificado da cadeia da Arrábida. Versão detalhada e a cores em Fonseca et al. (2014).

\subsection{A Plataforma do Cabo}

Uma das etapas mais marcantes da evolução do relevo da cadeia da Arrábida está relacionada com o embutimento de um nível erosivo em torno do 190 - 220 metros, genericamente denominado de Nível da Plataforma do Cabo. Esta forma de relevo erosiva, desenvolvida sobre as camadas do Jurássico médio ao Paleogénico, materializa- se a ocidente por uma superfície aplanada, balançada tectonicamente para oeste entre Sesimbra e o Cabo de Espichel (onde atinge 140 metros de altitude), por um conjunto de rechãs e topos aplanados ao longo do sopé WSW do Formosinho (a 200-225m) e pelo topo das Serras de S. Francisco, Gaiteiros e Palmela (220-250m) (CABRAL, 1993; MANUPPELLA et 
al., 1999). A superfície da Plataforma do Cabo tem sido interpretada como uma superfície de abrasão marinha pela regularidade do aplanamento, proximidade ao mar e presença de raros seixos rolados à superfície (RIBEIRO, 1935; DAVEAU e AZEVEDO, 1981; CABRAL, 1993).

Apesar da sua morfologia aplanada, a superfície da Plataforma do Cabo está tectonicamente deformada em diversos sectores. Entre o Cabo de Espichel e o marco geodésico do Facho (197m) encontra-se balançada para oeste por rejogo provável dos acidentes de Vale Cavalo e da Cova da Raposa (DAVEAU e AZEVEDO, 1981). A leste de Sesimbra encontra-se possivelmente deformada por uma falha de orientação NNW-SSE que produziu o levantamento e empolamento monoclinal da serra de Ares (Ribeiro, 1935) (Figura 7). Imediatamente a NNE, o relevo do Píncaro $(380 \mathrm{~m})$ poderá resultar de um deformação acentuada da Plataforma do Cabo, ou constituir um relevo residual acima dela (MANUPPELLA et al.,1999).

Numa análise regional, observa-se que a altitude do nível da Plataforma do Cabo aumenta de SW para NE, assumindo a altitude máxima de 250 e 230 metros no topo da serra de S. Francisco e colina de Palmela, respectivamente. Ao constatarmos que esta superfície erosiva se desenvolve de forma regular em torno dos 200-220 metros sobre os calcários compactos de idade jurássica, parece-nos difícil de aceitar que o topo da Serra de S. Francisco, tratando-se do seu prolongamento para NE, possa ser correlacionado com o nível da Plataforma do Cabo, sem a consideração de uma deformação tectónica posterior. Esta observação ganha consistência se considerarmos que o nível erosivo se encontra preservado a ESE, ao longo do topo da Serra dos Gaiteiros e Palmela, a uma altitude de 200-220 metros (Figura 7).

Diversas hipóteses têm sido colocadas no que respeita à idade da Plataforma do Cabo: Daveau e Azevedo (1981) atribuem a sua formação, com algumas reservas, ao Pliocénico inferior; Cabral (1993) propõe que esta tenha sido elaborada posteriormente ao segundo impulso tectónico da cadeia da Arrábida e após a génese do paleo-relevo que se observa ao longo da arriba ocidental, sendo provavelmente correlativa da superfície de colmatação do enchimento aluvial pliocénico, datando do Pliocénico superior ou do Quaternário inferior; Moniz (2010) correlaciona a paleotopografia fossilizada por sedimentos pliocénicos observada ao longo da arriba ocidental da Península de Setúbal com o sistema de vales nos quais assentam os sedimentos pliocénicos no interior do maciço da Arrábida e propõe uma idade Miocénica para a elaboração da Plataforma do Cabo, não descurando a possibilidade de retoque erosivo posterior no Placenciano ou Quaternário inferior.

Dados recentes sobre as variações eustáticas durante o Cenozóico indicam que o período entre 6 e 5 Ma foi caracterizado por uma variação positiva da curva eustática, colocando o nível médio das águas do mar cerca de 50 metros acima do nível atual (valor máximo registado para o período entre $9 \mathrm{Ma}$ e a atualidade) (MILLER et al., 2005). Se considerarmos que a $2^{\text {a fase }}$ de deformação da cadeia da Arrábida está situada entre 8 e 7 Ma e que a estrutura colapso de Palmela se situa entre 8 a $6.5 \mathrm{Ma}$, revela-se aceitável propor a elaboração da superfície erosiva da Plataforma do Cabo durante o Miocénico terminal, na medida em que esta trunca o dobramento da serra de S. Luís e a colina de Palmela. Esta hipótese ganha consistência se aceitarmos a atribuição de uma idade pliocénica aos sedimentos encontrados no interior do maciço, a uma altitude inferior a 200 metros.

\subsection{Cintura de relevo em estrutura monoclinal}

A norte dos relevos do Formosinho e S. Luís as bancadas mergulham em direção ao Sinclinal de Albufeira com uma inclinação variável de $50^{\circ}$ a $75^{\circ}$, diminuindo acentuadamente para norte. A erosão diferencial das camadas mais brandas do Jurássico superior, Paleogénico e Miocénico médio (margas, conglomerados, argilas e arenitos) permitiu a formação de relevos estruturais do tipo costeira, sendo os relevos positivos sustentados pelos calcários e calco-arenitos cretácicos, paleogénicos e miocénicos que limitam o bordo setentrional da cadeia da Arrábida. Localmente, a interferência de acidentes tectónicos provoca uma maior inclinação dos estratos, levando a que a tipologia das formas de relevo estruturais alterne entre crêt e hogback (Figura 6).

A oeste, entre o Cabo de Espichel e a Ribeira de Coina, o topo aplanado destes relevos desenvolve-se em torno dos 140-170 metros, formando duas cristas monoclinais (três nos sectores onde a erosão fluvial mais recuou para montante) talhadas nos calco-arenitos de idade cretácica. Estas apresentam uma geometria arqueada em função da disposição das bancadas ao longo do flanco norte do doma da Cova da Mijona (ver KULLBERG et al., 2000 para interpretação estrutu- 
ral), encontrando-se cortadas por uma rede de fraturas dispostas radialmente, intersetando-se segundo linhas perpendiculares à estratificação (KULLBERG et al., 1995). Para ENE, a altitude dos topos desenvolve-se em torno dos 170 metros até à margem esquerda da Ribeira de Coina, ponto a partir do qual a altitude aumenta progressivamente até atingir 255 metros na Serra de S. Francisco (Figuras 7, 8 e 9).

Após a formação dos anticlinais do Formosinho e S. Luís e posteriormente à criação da superfície da Plataforma do Cabo, segue-se uma fase erosiva caracterizada pelo encaixe da rede de drenagem, na qual a estrutura geológica desempenhou um papel fundamental, determinando, pela natureza do substrato, os sectores onde os processos erosivos teriam maior facilidade em penetrar. Esta longa fase evolutiva foi controlada pela variação do nível de base, imposta, quer pela variação do nível do mar, quer pelas movimentações tectónicas, regionais e locais.

A primeira etapa de degradação da superfície erosiva da Plataforma do Cabo está evidenciada na morfologia pela diminuição de altitude para norte do topo dos relevos em estrutura monoclinal com cornija dupla. Esta fase de degradação é caracterizada por uma superfície erosiva em glacis (hoje praticamente desmantelada), elaborada a partir do rebordo setentrional da Plataforma do Cabo (DAVEAU e AZEVEDO, 1980/81). Embora limitada ao sector ocidental, a interpretação morfológica apresentada por estas autoras pode ser facilmente estendida para leste, até à margem esquerda da ribeira de Coina, materializando-se por uma superfície erosiva estabelecendo ligação entre o bordo norte da superfície da Plataforma do Cabo (a norte da Serra de Ares, Píncaro e Terras do Risco) e o topo da crista monoclinal a 170 metros de altitude. Para leste desta ribeira, revela-se difícil atribuir o mesmo modelo de evolução, na medida em que a altitude da costeira aumenta bruscamente para 190-220 metros, até atingir a altitude máxima de 255 metros no topo da serra de $\mathrm{S}$. Francisco. Este facto, como vimos no ponto anterior, tem levado diferentes autores a considerar o topo da costeira a leste da ribeira de Coina como a extensão oriental do nível da Plataforma do Cabo.

O conjunto das formas de aplanamento identificadas em torno do 140-170 metros de altitude nas ribeiras de Coina, Alambre, Ajuda, Alcube e Cobre permite novamente reconstituir uma superfície erosiva estabelecendo ligação entre o topo dos cabeços mono- clinais a oeste da ribeira de Coina, os interflúvios das ribeiras de Alambre-Ajuda e Alcube-Corba, os topos do anticlinal do Viso e do sinclinal do Zimbral, e um conjunto de rechãs ao longo do flanco norte do anticlinal do Formosinho. Este nível, situado em torno dos 140170 metros, encontra-se assim claramente embutido no nível culminante da Plataforma do Cabo, delineando uma superfície côncava e explorando as bancadas mais brandas do Jurássico superior. No mapa geomorfológico (Figura 7) esta superfície é genericamente denominada de "Nível dos cabeços", seguindo a nomenclatura adotada por Daveau e Azevedo (1980/81).

\subsubsection{Análise topográfica e morfométrica}

Os perfis de altitude máxima, de amplitude de relevo e de nível de base (Figuras 8 e 9) permitem, à semelhança do que foi proposto por Ribeiro (1935), subdividir a crista monoclinal em três segmentos: de Palmela às Necessidades, das Necessidades à Ribeira de Coina, e daqui até ao bordo setentrional do Cabo de Espichel. Refira-se que a fronteira entre cada um dos segmentos é coincidente com lineamentos identificados nas fotografias aéreas e/ou falhas representadas na cartografia geológica (MANUPPELLA et al., 1999), dispostas em posição transversal à crista monoclinal (Figuras, 7, 8 e 9). Este facto sugere que estes segmentos constituem compartimentos tectónicos que terão rejogado de modo diferencial, controlados por um conjunto de estruturas que se desenvolvem segundo a orientação NW-SE a NNW-SSE. A deformação é progressivamente mais acentuada de WSW para ENE, traduzindo-se no aumento generalizado da linha de tendência de altitude máxima e do nível de base (Figura 8). Segundo Daveau e Azevedo (1980-81) e Pereira (1988), este padrão de deformação é igualmente observado na vertente meridional, entre o Cabo de Espichel e o Formosinho.

A continuidade lateral da crista monoclinal é interrompida pelo encaixe da rede hidrográfica proveniente da Plataforma do Cabo, Cabo de Ares, Píncaro e Formosinho. Toda a drenagem a oeste da ribeira de Alambre (inclusive) é do tipo cataclinal, revelando entathe ortoclinal apenas em segmentos de primeira ordem, ao longo de sectores com cornija dupla. O espaçamento de entalhe é regular e reduzido (espaçamento médio de $147 \mathrm{~m}$; desvio padrão de $23 \mathrm{~m}$ ) a oeste da ribeira da Pateira, aumentando de forma brusca para leste desta até à Rib. de Alambre (espaçamento médio de 2056m; 
desvio padrão de 822m) (Figura 8).

Em teoria e de um modo simplificado, a capacidade erosiva de um curso de água é, em primeira linha, controlado pela potência de escoamento, que por sua vez é controlada pela variação do declive e área de drenagem a montante. Os dois últimos parâmetros, quando analisados num contexto de evolução de cadeias ativas, tendem a variar em função da componente de movimentação vertical (PARKER, 1977; HOWARD, 1994; TUCKER e WHIPPLE, 2002). Em cenário de levantamento, observa-se o aumento da área de drenagem e do declive médio do canal principal.

Como se pode ver pelas figuras $8 \mathrm{E}$ e $8 \mathrm{~F}$, entre o Cabo de Espichel e a Rib. de Alambre, os parâmetros morfométricos de área de drenagem, amplitude do relevo, comprimento máximo de drenagem e grau de entalhe, apresentam uma tendência semelhante de aumento progressivo de WSW para ENE e uma forte correlação estatística entre variáveis (por ajustamento potencial), com valores de $\mathrm{R}^{2}$ a oscilar entre 0.94 e 0.66. Este aspeto revela a importância que os parâmetros morfométricos estudados possuem na variação lateral do grau de entalhe. Por outro lado, a ausência de um gradiente climático ao longo da área de estudo permite referir com relativa segurança que as variações observadas na morfologia e grau de entalhe resultam de anisotropias locais de natureza estrutural e morfológica.

Ou aspecto a destacar prende-se com a regularidade do espaçamento de entalhe a norte do Cabo de Espichel. Este fenómeno traduz o controlo estrutural imposto pela rede de fracturação de espaçamento regular e perpendicular à estratificação, presente em toda a extensão dos relevos em estrutura monoclinal a norte do doma da Cova da Mijona. A fraca amplitude de entalhe está associada à reduzida amplitude de relevo e diminuta área de drenagem para montante dos sectores analisados. A leitura dos perfis de altitude máxima e de amplitude de relevo revela ainda um ressalto positivo a
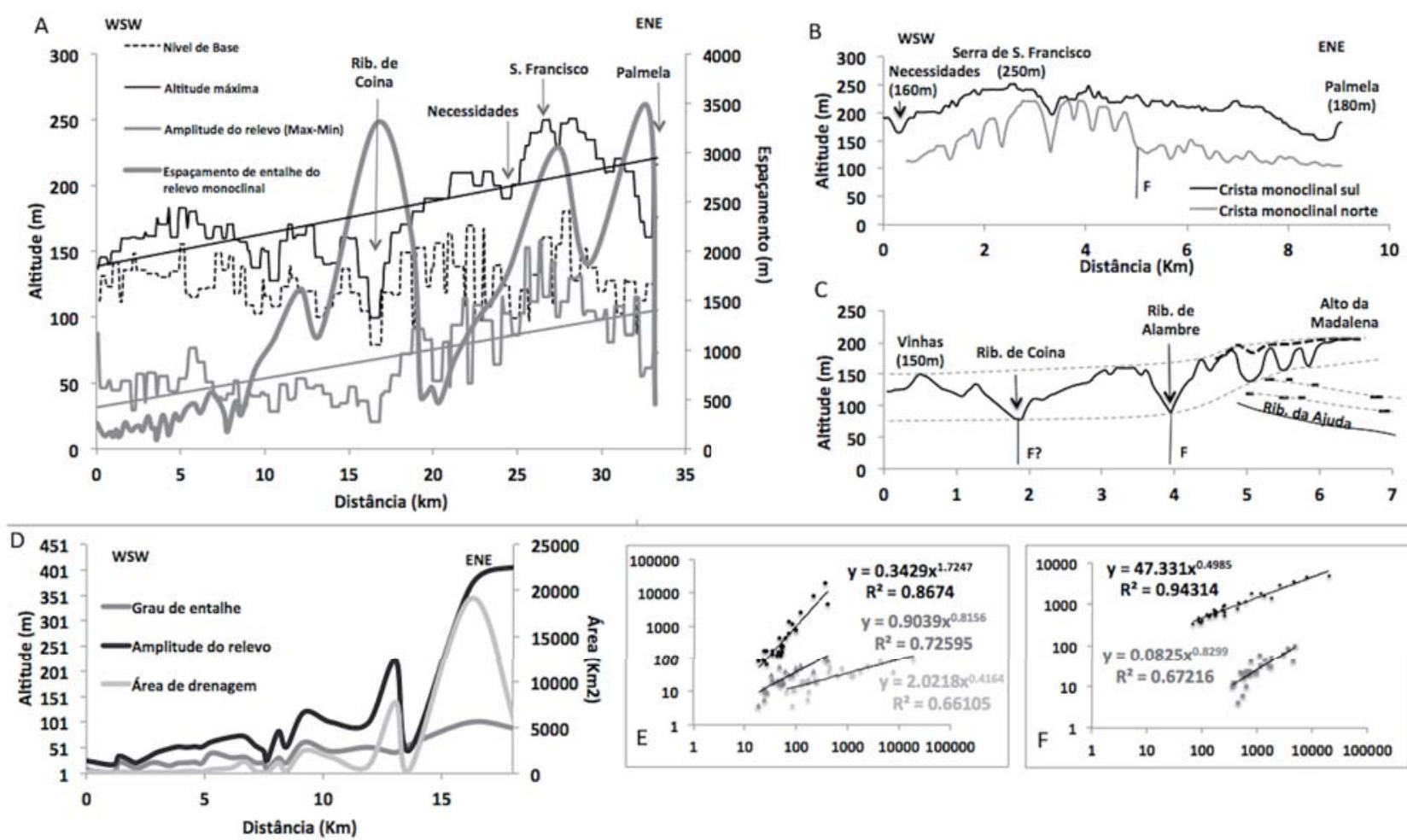

Figura 8 - Morfometria da cintura de relevos em estrutura monoclinal. Ver figura 9 para localização do perfis realizados: A) Variação WSW-ENE ao longo do perfil A-E da altitude máxima, nível de base, amplitude de relevo e espaçamento de entalhe; B) Perfil topográfico (B-C) e controlo tectónico ao longo do topo da crista monoclinal entre o Alto das Vinhas e o Alto da Madalena; C) Perfil topográfico (D-E) e controlo tectónico ao longo do topo da crista monoclinal entre Palmela e as Necessidades; D) Variação WSW-ENE (entre Cabo de Espichel - Rib. Alambre) da área a montante, relevo e encaixe da rede de drenagem; E) Correlação entre variáveis morfométricas por ajuste potencial em escala log/log.; Preto - Relevo vs. Área de drenagem; Cinzento escuro - Relevo vs. Entalhe; Cinzento claro - Área de drenagem vs. Entalhe; F) Correlação entre variáveis morfométricas por ajuste potencial em escala log/log: Preto - Área de drenagem vs. Comprimento máximo de drenagem; Cinzento escuro - Comprimento máximo de drenagem vs. Entalhe. 
oeste da ribeira da Pateira, no alinhamento do acidente tectónico de Vale Cavalo. Daveau e Azevedo (1980-81) identificam esta falha como uma das potenciais responsáveis pelo balançamento para oeste da Plataforma do Cabo. O facto de este acidente ser identificado ao longo do perfil de altitude máxima poderá indicar que ele se manteve ativo posteriormente à formação do nível erosivo dos Cabeços.

Para leste da ribeira da Pateira e até à ribeira de Alambre, o aumento do entalhe aparenta estar correlacionado com: I) o aumento gradual da área de drenagem e da amplitude do relevo entre os sectores entalhados e as áreas a montante localizadas no topo da Serra de Ares, Píncaro e Serra do Formosinho; II) o progressivo aumento da componente de deformação vertical para ENE; III) a transição para um contexto litológico distinto, dominado pelos materiais mais brandos do Jurássico superior (conglomerados, grés e argilas).

Dos degraus identificados ao longo dos perfis realizados, aquele que separa a ribeira de Coina do restante sector oriental de crista monoclinal é talvez o mais importante. Este é afectado por acidentes de orientação NW-SE a NNW-SSE que, pela sua geometria, favorecem a hipótese de um levantamento progressivamente mais acentuado dos compartimentos a leste (Figuras 9A e 9B). Ribeiro (1866) identifica uma falha em desligamento esquerdo de orientação NNW-SSE com um rejeito de aproximadamente 500 metros no local onde a ribeira de Coina cruza a crista monoclinal. Este aspecto é também referido por Choffat (1908), não sendo no entanto possível confirmar a sua presença devido à topografia da região e à cobertura de areias finas. Azevedo (1982) corrobora, em parte, as observações efetuadas por Ribeiro (1866), encontrando evidências estratigráficas e topográficas de rutura superficial numa falha de orientação NNW-SSE, localizada a norte da costeira (Figura 9), em dois períodos do Quaternário: I) posteriormente à deposição do conglomerado de Belverde, com abatimento relativo do bloco ocidental e consequente erosão no bloco oriental; e II) posteriormente à sedimentação da Formação do Marco Furado, exibindo um comportamento cinemático similar e com separações verticais progressivamente maiores para norte (max. 30m). Embora, de acordo com Manupella et al. (1999), esta falha não apareça identificada sobre os sedimentos pliocénicos, esta pode ser recuperada no seu alinhamento para sul, associando-se aos restantes acidentes de orientação NW-SE a NNW-SSE, responsáveis pela subdivisão da crista monoclinal em sub-compartimentos tectónicos. Tomando como referência o conjunto de formas aplanadas entre $130 \mathrm{e}$ 220 metros ao alongo do troço montante das ribeiras de Coina e Alambre, é inclusivamente possível constatar um desfasamento de cerca de 20 metros (mínimo 10m, máximo $30 \mathrm{~m}$ ) entre os sectores a oeste e leste dos acidentes identificados, estendendo-se a deformação para sul até ao cabeço do Formosinho (Figura 9).

De acordo com Azevedo (1982), as ribeiras de Coina e Alambre já existiriam aquando da deposição do Conglomerado de Belverde, constituindo afluentes do pré-Tejo. Posteriormente, estas terão contribuído com grande parte do material depositado a norte da crista monoclinal, correspondente à Formação de Marco Furado. Durante as fases iniciais de evolução destes segmentos de drenagem, o escoamento processar-se-ia em função de um nível de base situado um pouco abaixo dos 100 metros de altitude. A mudança brusca de direção de escoamento para NE (a cerca de 120 metros de altitude), rumo ao Mar da Palha, pode estar relacionado com o padrão de sedimentação da Formação de Marco Furado, criando um obstáculo ao desenvolvimento da drenagem para NW, ou com um processo de subsidência acentuado no sector do Barreiro-Montijo, forçando a captura por erosão remontante em direção a NE (AZEVEDO, 1982).

Para ENE da Ribeira de Alambre, a altitude dos relevos de costeira aumenta progressivamente até ao topo da Serra de S. Francisco, encontrando-se suspensos a sul sobre os vales das Ribeiras da Ajuda, Alcube e Cobro. No entanto, o perfil longitudinal revela a presença de portelas (windgaps), que rebaixam localmente a altitude do topo (Figura 9B): resultarão estas formas da erosão diferencial ao longo de descontinuidades, por erosão remontante a partir da base dos relevos? ou constituirão evidências de uma paleo-drenagem de sentido S-N, a partir dos altos do Formosinho e S. Luís, anteriormente ao embutimento erosivo das Ribeiras da Ajuda, Alcube e Cobro?

Pese embora a presença de portelas ao longo do troço compreendido entre a Ribeira de Alambre e Pamela, é entre a Ribeira de Alambre e o Alto da Madalena que as evidências morfológicas de uma eventual drenagem vinda de sul se encontram melhor preservadas (Figura 9B). De facto, no decorrer do trabalho de foto-interpretação, desde cedo se notou a presença de dois entalhes na crista monoclinal (E1 e E2) imediatamente a ENE da Ribeira de Alambre (Figura 9B). A cabeceira 

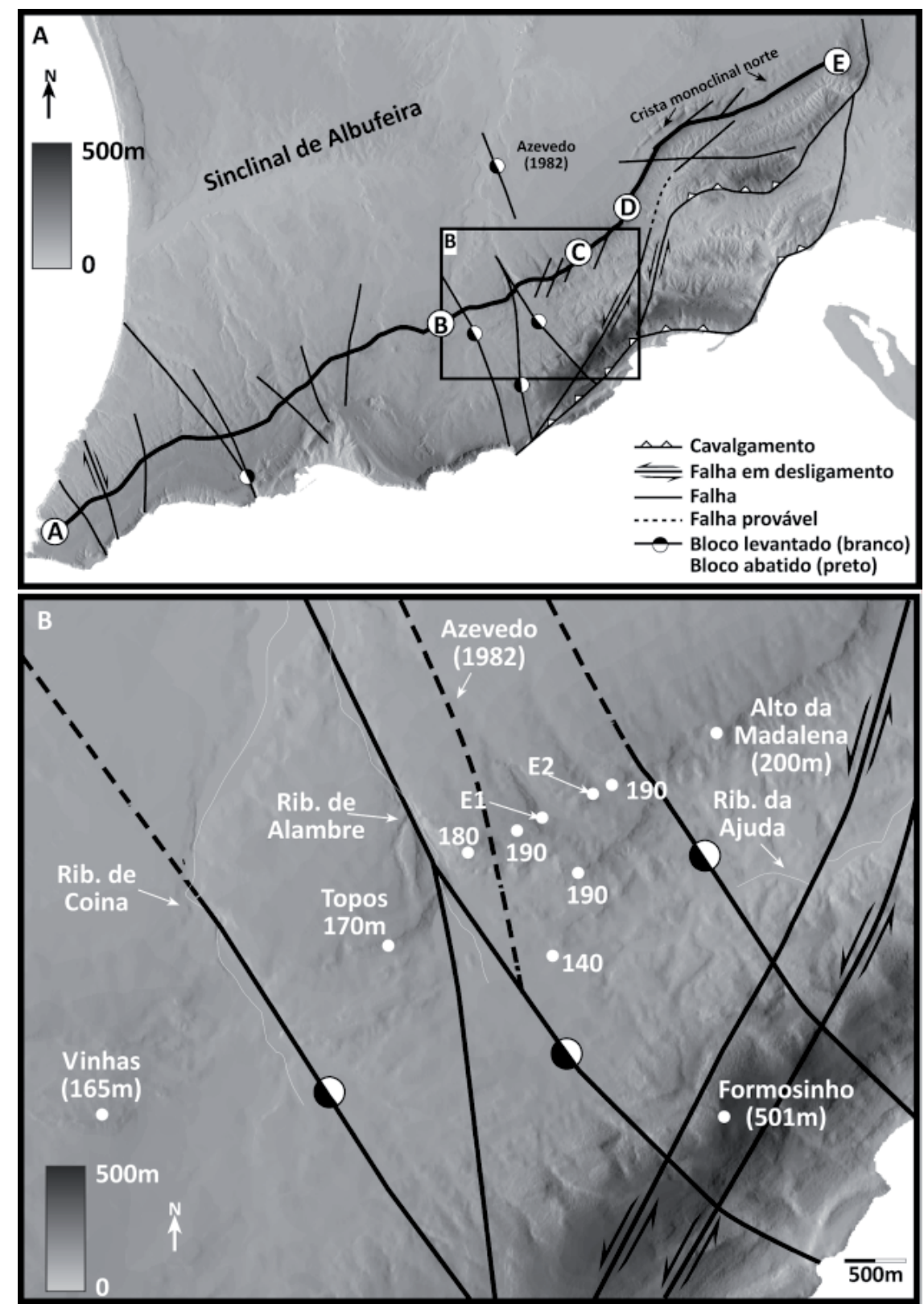

Figura 9 - Cintura de relevos em estrutura monoclinal: A) Enquadramento estrutural e localização dos perfis realizados; B) Papel de estruturas tectónicas na compartimentação e levantamento diferencial da área compreendida entre a ribeira de Coina e Alto da Madalena.

para os referidos entalhes localiza-se a 190-170 metros de altitude, a uma distância aproximada de 780 metros para SE, sobre uma cornija de calco-arenito de idade cretácica (Figuras 7 e 9B). Para sudeste deste local as altitudes caiem bruscamente para o domínio do vale da Ribeira da Ajuda.

Mesmo considerando o alinhamento destas formas com alguns dos acidentes identificados na cartografia geológica, a proximidade geográfica e a similitude da morfologia de entalhe comparativamente àquela obser- vada nas ribeiras a oeste, torna-se difícil interpretar a evolução destas formas na dependência de uma erosão remontante a partir da depressão periférica a norte, considerando a progressiva diminuição do grau de entalhe e aumento da altitude do nível de base para ENE. Por outro lado, não é de todo evidente que a altitude, distância da cabeceira atual e área a montante dos sectores entalhados, se correlacionem com o grau de entalhe observado. Somos assim tentados a assumir a hipótese de estas formas de relevo serem contemporâ- 
neas das primeiras fases de entalhe da crista monoclinal e associadas a uma drenagem vinda de sul, com origem provável no Formosinho.

Esperando compreender se as presentes áreas de drenagem e amplitude de relevo a montante de E1 e E2 se correlacionam com o grau de entalhe a jusante, tomaram-se como referência as expressões obtidas para as retas de correlação potencial entre variáveis morfométricas previamente obtidas. Ao utilizar as equações que relacionam a amplitude do relevo, a área e o comprimento máximo de drenagem com o entalhe do relevo monoclinal, torna-se possível obter os valores esperados para cada variável morfométrica, atribuindo a $\mathrm{Y}$ os valores de entalhe observados em E1 e E2. Esta abordagem assenta no pressuposto de que as fórmulas utilizadas explicam, na dependência do valor de correlação obtido, a variação espacial do grau de entalhe.

Da resolução das respetivas equações, obtiveram-se os resultados expressos na Tabela 1. Os resultados obtidos, em nada comparáveis com os valores atuais (Tabela 1), favorecem a colocação da cabeceira para os entalhes analisados ao longo da Serra do Formosinho. Esta hipótese revela-se particularmente ajustada ao observar os valores esperados de comprimento máximo de drenagem. No entanto, se tivermos em conta que a altitude do talvegue em E1, se situa em torno dos 138 metros (E1) e somarmos a este, o valor de amplitude de relevo esperado $(140 \mathrm{~m})$, colocamos a cabeceira deste segmento de drenagem a cerca de 280 metros de altitude. Se aplicarmos o mesmo raciocínio para o entalhe E2, colocamos a sua cabeceira a cerca de 250 metros. Os valores obtidos são claramente superiores à presente altitude das cabeceiras ao longo da crista cretácica, mas inferiores à altitude atual da Serra do Formosinho, presentemente situada em torno dos 500 metros. Esta hipótese implica considerar um levantamento superior a 200 metros do sector a montante da crista monoclinal durante um período que se situa de forma incerta entre o final do Pliocénico e o Quaternário inferior.

Tabela 1: Dados morfométricos observados nos entalhes E1 e E2 entre a ribeira de Alambre e o Alto da Madalena e resultados esperados, calculados a partir das formulas expressas na Figura 8E e 8F.

\begin{tabular}{|c|c|c|c|c|c|c|c|c|c|c|}
\hline & \multirow{2}{*}{$\begin{array}{c}\text { Amplitude } \\
\text { máxima de } \\
\text { entalhe (m) }\end{array}$} & \multirow{2}{*}{$\begin{array}{c}\begin{array}{c}\text { Altitude do } \\
\text { fundo de vale } \\
\text { (m) }\end{array} \\
\text { Obs. } \\
\end{array}$} & \multicolumn{2}{|c|}{$\begin{array}{c}\text { Altitude da } \\
\text { cabeceira (m) }\end{array}$} & \multicolumn{2}{|c|}{ Relevo (m) } & \multicolumn{2}{|c|}{$\begin{array}{c}\text { Comprimento de } \\
\text { drenagem (m) }\end{array}$} & \multicolumn{2}{|c|}{$\begin{array}{c}\text { Área de } \\
\text { drenagem }\left(\mathrm{km}^{2}\right)\end{array}$} \\
\hline & & & Obs. & Esp. & Obs. & Esp. & Obs. & Esp. & Obs. & Esp. \\
\hline E1 & 51 & 135 & 175 & 280 & 40 & 140 & 645 & 2307 & 301 & 2326 \\
\hline E2 & 36 & 155 & 175 & 250 & 20 & 90 & 478 & 1516 & 225 & 1007 \\
\hline
\end{tabular}

O facto de as ribeiras de Coina e Alambre já existirem aquando da deposição da Formação de Belverde e Marco Furado e devido à deformação destes depósitos pelos acidentes descritos, obriga a colocar o levantamento do compartimento oriental durante o Quaternário. A suspensão do troço montante da ribeira de Alambre relativamente à ribeira de Coina fica assim explicada pelo acentuar da componente de deformação vertical para leste, por rejogo provável do acidente da ribeira de Coina. As evidências de paleo-vales situadas entre a ribeira de Alambre e o Alto da Madalena serão assim contemporâneas dos entalhes mais a ocidente, tendo sido capturadas por erosão remontante da ribeira da Ajuda durante a primeira fase de entalhe da crista monoclinal. A diminuição gradual do grau de entalhe de oriente para ocidente entre E2 e a ribeira de Coina e o respetivo aumento da altitude de nível de base, revela que o processo de levantamento e captura deverá ter ocorrido de forma progressiva, em consequência de sucessivas ruturas dos planos de falha ou associado a um movimento lento de todo o compartimento. Por outro lado, se aceitarmos a validade da análise morfométrica realizada para os entalhes E1 e E2 e enquadrarmos os resultados no conjunto das observações efetuadas ao longo da crista monoclinal, somos obrigados a levantar a hipótese de as cabeceiras para os entalhes E1 e E2 estarem situadas no topo da Serra do Formosinho, numa fase em que esta estaria a uma altitude consideravelmente mais baixa, associadas a bacias maioritariamente desenvolvidas sobre a formação do Jurássico superior, em torno dos 250-280 metros.

\subsection{Os vales e a depressão periférica}

Como já foi demostrado, a rede hidrográfica desempenhou um papel fundamental na estruturação 
do relevo da cadeia da Arrábida, entalhando o substrato ao longo dos afloramentos menos resistentes do Jurássico superior e Paleogénico, a partir da degradação da superfície erosiva culminante da Plataforma do Cabo e nível dos Cabeços. A rede de drenagem evoluiu em função da posição da linha de costa, estabelecendo ligação entre o domínio tectónico de levantamento da serra da Arrábida e o domínio subsidente das depressões periféricas, a norte (Sinclinal de Albufeira) e a sudeste (depressão de Setúbal).

As cumeadas Cabo de Espichel-Formosinho e Formosinho-Palmela (Figura 5) subdividem a cadeia da Arrábida em três domínios morfo-hidrográficos: 1) o sistema de vales com escoamento para norte a noroeste, com cabeceira ao longo do topo da Serra de S. Francisco, Formosinho e Plataforma do Cabo ocidental; 2) o sistema de vales de orientação E-W a ENE-WSW estabelecidos nas formações brandas do Jurássico superior e com cabeceiras nas serras de S. Francisco, Formosinho e S. Luís; 3) o sistema de vales e valeiros com drenagem para sul, desenvolvidos na vertente costeira meridional. Este último grupo será descrito na secção 4.5 deste artigo.

A norte da crista monoclinal, a drenagem entalha os sedimentos arenosos de idade pliocénica ao longo de uma vasta superfície em glacis, suavemente inclinada para norte, estabelecida entre 100-120 e 70 metros de altitude, denominada de "Nível Principal" (ver mapa geomorfológico). Esta superfície será correlativa da deposição do Conglomerado de Belverde (DAVEAU e AZEVEDO, 1980/81), tendo sido elaborada por ação fluvio-marinha, desmantelando uma espessura considerável de sedimentos pliocénicos. A sua formação ter-se-á verificado durante o final do Pliocénico ou no início do Quaternário, em função de um nível do mar relativo alto, de origem glacio-eustático, situado entre 2 a 1,6 Ma ou entre 1,4 a 1Ma (CABRAL, 1993), tendo sido posteriormente fossilizada pelos derrames torrenciais da Formação de Marco Furado. O facto da rede de drenagem entalhar a superfície erosiva principal, desenvolvida nos sedimentos pliocénicos e quaternários, leva a colocar a sua evolução em função das variações do nível de base impostas pelas movimentações tectónicas e pelas variações eustáticas ocorridas no Quaternário.

A ribeira de Coina, em virtude das deformações quaternárias descritas no ponto anterior, constitui uma fronteira geomorfológica entre os domínios ocidental e oriental da depressão periférica setentrional. Para leste, com cabeceira ao longo da crista monoclinal entre Palmela e o Alto da Madalena, o nível principal encontra-se pouco degradado em virtude de uma drenagem com encaixe reduzido e fracamente hierarquizada, estabelecida sobre os sedimentos argilo-arenosos e cascalhentos de idade pliocénica e quaternária. Para oeste, a linha divisória de águas recua para sul, estabelecendo-se ao longo do topo da serra do Formosinho até ao Cabo de Espichel (Figura 5A). Ao longo deste sector, a drenagem é concordante com a estrutura entalhando, segundo a direção S-N a ESE-WNW, as bancadas do Jurássico, Cretácico e Paleogénico. Ao atingir a depressão periférica, a rede hidrográfica entalha o nível principal com uma amplitude de 30 a 50 metros, isolando interflúvios alongados segundo a orientação S-N a SE-NW.

O controlo estrutural na rede de drenagem é particularmente evidente ao longo da cabeceira das bacias 1 a 9 (Figura 5A e 5B) com entalhe ortoclinal em segmentos de primeira ordem. Como já foi referido, a regularidade do espaçamento de entalhe da crista monoclinal indicia o controlo por parte de uma densa rede de fraturas perpendiculares à estratificação de orientação NW-SE a N-S. Algumas destas linhas de fraqueza controlam localmente o traçado dos principais cursos de água, evidenciando um deslocamento em cisalhamento direito, concordante com o comportamento cinemático das estruturas identificadas no sector ocidental da Arrábida (Figura 7). É ainda notória a mudança brusca da direção de escoamento entre os sectores a ocidente e oriente da ribeira da Pateira.

Os resultados obtidos na análise morfométrica das principais bacias hidrográficas a oeste da Ribeira de Coina permitem tirar algumas conclusões relativamente à evolução deste sector da Arrábida. As curvas hipsométricas normalizadas indicam um progressivo aumento da maturidade das bacias de ocidente para oriente, em concordância com a diminuição do Rácio de Elevação-Relevo e do Declive médio (Figura 5C e 5D). As bacias 3 a 7 são francamente assimétricas (valores de IA inferiores a 0.5 ), com posicionamento do canal principal a norte do eixo geométrico das bacias. As bacias 8 e 9 apresentam uma forte simetria, com valores de IA próximos de 0,5. Esta tendência é acompanhada pelo aumento dos valores de ICA, traduzindo-se num maior alongamento das bacias 7 a 9 comparativamente ao observado para as bacias costeiras (1 a 6) (Figura $5 \mathrm{C}$ e 5D).

$\mathrm{Na}$ evolução da rede hidrográfica do sector 
ocidental, são evidentes as capturas de segmentos de drenagem de orientação S-N a SSE-NNW, indiciando uma organização recente da drenagem em função da posição da linha de costa situada a oeste (DAVEAU e AZEVEDO, 1980-81). O sector terminal das ribeiras 1 a 6 encontra-se alcandorado relativamente ao nível atual do mar, apresentando uma tendência de diminuição da altura da rutura de declive terminal para norte em direção à Lagoa de Albufeira (DAVEAU e AZEVEDO, 1980/1981). Apesar do aumento da área das bacias hidrográficas, de sul para norte, as autoras atribuem este facto a um balançamento neotectónico para norte.

Ao longo dos sectores mais elevados, a drenagem acompanha o sentido de inclinação da estratificação. Ao contrário das bacias 1 a 6 , que a partir do sector intermédio tendem a infletir para oeste, as bacias 7 a 9 mantêm-se fiéis ao traçado definido pela estratificação, atingindo o eixo do Sinclinal de Albufeira na Lagoa com o mesmo nome, a cerca de $8 \mathrm{~km}$ a norte da cabeceira. Se tivermos em consideração que as cabeceiras das bacias analisadas se encontram sensivelmente à mesma altitude, revelando um aumento pouco significativo de cerca de 50 metros (ao longo de $14 \mathrm{~km}$ ) entre as bacias 1 e 9 , podemos concluir que os resultados expressos pelas curvas hipsométricas normalizadas, Rácio de Elevação-Relevo e Declive médio, resultam da conjugação de três fatores determinantes: I) o controlo estrutural exercido pela atitude das bancadas ao longo do flanco sul do Sinclinal de Albufeira, pré-definindo, por diminuição da inclinação das camadas para norte, um perfil longitudinal côncavo (regularizado e maduro) para as bacias 7 a 9; II) a proximidade ao nível de base (maior de este para oeste), em junção com o posicionamento do eixo do Sinclinal de Albufeira a cerca de $8 \mathrm{~km}$ a norte, exerce influência na diminuição do declive médio e do rácio Elevação-relevo de ocidente para oriente; III) o aumento do comprimento das bacias e a progressiva diminuição da altitude da rutura de declive terminal dos cursos de água ocidentais favorecem uma maior regularização e, consequentemente, uma maior maturidade, dos perfis longitudinais.

A simetria das bacias 7 a 9 está parcialmente ligada com o facto da drenagem se desenvolver de acordo com a estrutura. No entanto, dada a natureza friável do substrato da região, seria de esperar que, num contexto de estabilidade tectónica, as bacias hidrográficas assumissem uma geometria mais compacta seguindo os modelos de evolução propostos na bibliografia (PARKER, 1977; HOWARD, 1994). Face ao conjunto de evidências morfológicas e morfométricas identificadas em toda a região ocidental, atribuímos o forte alongamento das bacias 7 a 9 a um provável balançamento neotectónico para noroeste de toda a região, a norte da falha de Vale Cavalo. Para ocidente deste acidente, o padrão de deformação é claramente distinto, traduzindo-se num balançamento das superfícies aplanadas e níveis marinhos para oeste.

Para leste, a Ribeira de Coina congrega a totalidade do escoamento proveniente da serra do Formosinho e do flanco norte do Alto da Madalena e serra de S. Francisco. No conjunto, a bacia da Ribeira de Coina é francamente assimétrica, com o posicionamento do canal principal a oeste. Para montante do sector onde a ribeira entalha a crista monoclinal, a direção de escoamento é oblíqua à disposição da crista monoclinal, estando o eixo da bacia posicionado a leste, controlado estruturalmente pela falha de Coina.

Para sudeste, a drenagem proveniente da Serra do Formosinho e S. Luís atinge a costa meridional na zona do Outão e depressão de Setúbal, maioritariamente por 5 bacias hidrográficas desenvolvidas segundo a orientação WNW-ESE a NNW-SSE (ribeiras da Melra - B11, Ajuda e Alcube - B12, Quinta da Lage e Corva - B14) (Figura 5A). O traçado dos segmentos de drenagem de ordem superior é fortemente condicionado pela estrutura, entalhando em posição ortoclinal as camadas mais brandas do Jurássico superior e Paleogénico. Os restantes segmentos de drenagem ( $\left(1^{\mathrm{a}}\right.$ e $2^{\mathrm{a}}$ ordem de Strahler) desenvolvem-se em posição cataclinal e anaclinal, nos flancos dos anticlinais do Formosinho e S. Luís e no flanco sul da crista monoclinal entre o Alto da Madalena e Palmela, respetivamente. Localmente, a rede hidrográfica é controlada por acidentes tectónicos de orientação NE-SW, N-S e NW-SE, sendo particularmente notório o desvio (ou adaptação) do traçado do canal principal da ribeira da Ajuda, em concordância com o deslocamento em cisalhamento esquerdo das falhas de orientação NE-SW que estabelecem ligação entre os cavalgamentos do Formosinho e S. Luís (Figura 7).

A partir do nível superior da Plataforma do Cabo é possível identificar pelo menos três níveis de embutimento erosivo: I) o nível dos cabeços (140-170m), anteriormente descrito; II) o nível dos vales (90-140m); III) o nível atual $(0-80 \mathrm{~m})$ (Figura 7). Os interflúvios que separam as ribeiras de Alambre-Ajuda e Alcube-Corva encontram-se a aproximadamente 140-150 
metros e 150-160 metros, respetivamente, definindo a altitude de partida para o desenvolvimento dos vales centro-orientais. Para jusante, a altitude deste nível diminui gradualmente de 130-120 para 100-80 metros, permitindo a reconstituição de uma paleo-superfície de fundo de vale estabelecendo ligação entre os sectores mais elevados e a costa sudeste. A presença de rechãs a altitudes comparáveis ao longo das três ribeiras, convergentes para um nível de base comum, sugere uma organização da rede hidrográfica em função de um litoral situado um pouco abaixo do 100 metros de altitude (ALCOFORADO, 1981). A concordância altimétrica das rechãs na desembocadura dos principais vales com a Formação do Marco Furado (100-110 m) leva a supor que sejam contemporâneas do Nível erosivo Principal situado a norte da crista monoclinal.

As rechãs ao longo da margem esquerda da ribeira da Ajuda (a sul do Alto da Madalena) revelam capturas sucessivas por entalhe da rede hidrográfica, com migração do canal principal para sul. Ao longo do troço final da ribeira, a disposição das formas aplanadas a sul do S. Luís e a oeste do Viso (rechã em torno dos 80 metros de altitude; portela situada a 80 metros acima do nível do mar entre o S. Luís e o Viso) sugerem uma evolução semelhante, com captura e migração do canal principal para sudeste (Figura 7).

Alcoforado (1981) refere que as rechãs a 120 100 metros ao longo da ribeira da Ajuda, preservam uma cobertura de areias finas e pouco argilosas, com evidências de eolização. Alguns destes depósitos surgem marcados na carta geológica 1:50,000, sendo no entanto consensual na bibliografia (ALCOFORADO, 1981; AZEVEDO, 1982) que a sua distribuição é muito superior, cobrindo retalhos aplanados em torno dos 100 metros de altitude, a sul da serra de S. Luís.

A ribeira da Melra, situada a sul da atual desembocadura da ribeira da Ajuda, apresenta uma evolução semelhante às restantes ribeiras orientais. $\mathrm{O}$ embutimento erosivo inicial terá tido início em torno dos 150 - 140 metros de altitude, diminuindo progressivamente de altitude para sudeste até aos 100 metros, junto ao litoral do Outão. A inflexão brusca do canal principal para norte, ao longo da secção terminal da ribeira, sugere uma adaptação recente à estrutura por descida do nível de base.

Entre o S. Luís e os Gaiteiros desenvolve-se uma pequena bacia hidrográfica (ribeira da Quinta da Lage -
B13) de orientação E-W a SE-NW. No sector montante, a ribeira entalha o contacto entre o Jurássico inferior e o Jurássico superior segundo a orientação W-E, desenvolvendo-se entre os 180 e os 160 metros de altitude. Ao atingir o bordo sudeste da Serra, fronteira estrutural imposta pelo cavalgamento S. Luís - Gaiteiros, a ribeira inflete bruscamente para sudeste em direção à depressão periférica de Setúbal. No entanto, um conjunto de rechãs a cerca de 160-150 de altitude, dispostas no alinhamento do troço montante da ribeira (Figura 7), sugere um traçado original segundo a orientação E-W, anterior ao seu desvio para sudeste. Este nível será provavelmente correlativo do topo dos interflúvios das ribeiras da Ajuda, Alcube e Corva, tendo o escoamento sido desviado, possivelmente em resposta ao levantamento recente do compartimento norte, limitado pelo cavalgamento de $\mathrm{S}$. Luís - Gaiteiros.

O forte controlo estrutural no traçado da rede hidrográfica das bacias orientais, imposto pela natureza friável do substrato jurássico, dificulta, ao contrário do que foi efetuado para o sector ocidental, a extração de informação referente à interferência de processos tectónicos na sua evolução. É no entanto interessante constatar o traçado das curvas hipsométricas normalizadas (Figura 5C), claramente afetado pelo forte declive e amplitude de entalhe ao longo do troço final das ribeiras da Ajuda e Melra e pelo aumento de altitude imposto pelo cavalgamento de S. Luís - Gaiteiros.

\subsection{A vertente costeira meridional e a depressão de Sesimbra}

A singularidade da cadeia da Arrábida relativamente às restantes Serras calcárias do país prende-se com o contacto abrupto que esta estabelece com o oceano Atlântico ao longo da fachada meridional. Com um comando médio de 200 metros (mínimo 130m; máximo $300 \mathrm{~m}$ ), a vertente costeira apresenta uma morfologia complexa, marcada pela presença de formas de erosão marinha e de evolução subaérea. A altitude do topo aumenta para oriente em concordância com o aumento da amplitude de deformação tectónica (PEREIRA, 1988). O litoral é irregular, sendo caracterizado por reentrâncias controladas pelo traçado da estrutura geológica (ex. Portinho da Arrábida) ou pela presença de litologias mais brandas (ex. Sesimbra) (Figura 7).

No entanto, a descrição pormenorizada destas formas de relevo não se enquadra nos objetivos do pre- 
sente trabalho. Diversos autores têm vindo a trabalhar nesta temática (Daveau e Azevedo, 1980/81; Pereira, 1988; Pereira et al. 2007; Pereira e Regnauld, 1994; Regnauld et al. 1995; Manupella et al. 1999) pelo que nos limitamos a uma descrição sucinta dos principais traços morfológicos contidos no mapa geomorfológico (Figura 7).

O perfil da vertente costeira evidencia a presença de níveis de erosão marinhos escalonados, observando-se o aumento da altitude para oriente acompanhando a tendência da região. As rechãs mais altas, possivelmente correlativas do nível do cabeços, estão situadas em torno de 140 a 170 metros de altitude e apresentam uma tendência de balançamento para oeste, em concordância com a deformação do nível da Plataforma do Cabo (Daveau e Azevedo, 1980/81). As rechãs mais baixas apresentam deformação longitudinal mais recente, ligada a falhas transversais ao litoral, o que tem dificultado a atribuição de idades para a sua elaboração. Sobre estas rechãs encontram-se preservados sedimentos de praia constituídos por areias soltas ou consolidadas, com calhaus rolados (PEREIRA e REGNAULD, 1994; REGNAULD et al., 1995; PEREIRA et al. 2007).

Ao longo da fachada sul, a rede de drenagem é pouco desenvolvida, sendo maioritariamente caracterizada por barrancos e valeiros de traçado retilíneo, fortemente controlados pelo declive e, localmente, por acidentes tectónicos de orientação transversal ao traçado da vertente. $O$ grau de entalhe é progressivamente mais acentuado para o topo, sobretudo ao longo do sector compreendido entre o Cabo de Espichel e Sesimbra, onde a drenagem se estende para norte sobre a Plataforma do Cabo. De todas as formas erosivas, destaca-se neste sector o vale da Ribeira da Mareta que progride pela Plataforma do Cabo ao longo de aproximadamente $10 \mathrm{~km}$, assumindo uma geometria curva segundo a orientação SE-NW a E-W, acompanhando o traçado das bancadas calcárias do Jurássico médio-superior. Daveau e Azevedo (1980/1981) atribuem a evolução do vale da Ribeira da Mareta a processos fluvio-cársicos, durante a fase de elaboração do Nível dos Cabeços.

A continuidade da vertente costeira é apenas interrompida pela reentrância da depressão diapírica de Sesimbra. Esta constitui uma forma de relevo estrutural resultante da erosão diferencial das camadas da Dagorda. Os bordos desta depressão assumem uma geometria triangular formada por dois alinhamentos de relevos convergentes para norte construídos sobre as litologias mais resistentes à erosão do Jurássico inferior e coincidentes com o traçado de falhas de orientação NNW-SSE e NE-SW (KULLBERG et al. 2000). De acordo com estes autores, a idade mais provável para a fase principal do diapirismo salino em Sesimbra será tardi-Cretácica, não sendo no entanto de excluir a possibilidade de terem ocorrido movimentações múltiplas no final do Cretácico, entre o Oligocénico e o Miocénico e durante a inversão Miocénica. A estrutura está fortemente deformada e fraturada, expondo materiais do Jurássico inferior, médio e superior, ocorrendo injeções de material margo-salino ao longo de acidentes de orientação NNW-SSE e NE-SW. O núcleo da depressão foi progressivamente escavado pela ação conjunta de processo marinhos e sub-aéreos, evidenciada pela presença de rechãs escalonadas e de knicks nos segmentos de drenagem a altitude comparáveis.

\section{Considerações Finais Sobre a Evolução do Relevo}

Um dos problemas da interpretação morfológica e morfométrica apresentada no presente trabalho prende-se com a dificuldade de limitar temporalmente cada um dos eventos descritos. A cronologia de eventos pós-Miocénicos na região da Península de Setúbal (com exceção dos níveis marinhos mais baixos ao longo da costa meridional), tem sido estabelecida por critérios relativos, para os quais não foram ainda apresentadas datações absolutas. O desconhecimento da espessura dos sedimentos pliocénicos e a ausência de datações para os limites superiores e inferiores desta formação, não permite resolver grande parte dos problemas relativos à evolução do relevo. Procuraremos de seguida analisar o conjunto das observações anteriormente apresentadas, e extrair, na medida do possível, conclusões a partir do conhecimento atual da tectónica da Arrábida.

O Nível da Plataforma do Cabo, apesar de constituir a referência a partir da qual se processa o embutimento erosivo plio-quaternário, é aquele sobre o qual se levantam mais questões. Como vimos ao longo deste trabalho, o aplanamento principal desta forma de relevo poderá ser anterior à deposição da séria pliocénica, em associação aos níveis eustáticos elevados do Miocénico, ou ser-lhe correlativo (DAVEAU e AZEVEDO, 198081; CABRAL, 1993; MONIZ, 2010). A resposta para esta questão reside, em parte, na natureza e proveniência dos sedimentos ditos pliocénicos encontrados no interior do maciço: I) na confirmação de uma idade pliocénica, 
teremos que colocar a formação do nível da Plataforma do Cabo anteriormente à sua deposição e assumir a hipótese, à semelhança do modelo apresentado por Moniz (2010), da paleo-topografia fossilizada ao longo da costa ocidental ser correlativa dos principais vales da Serra nos quais ocorrem sedimentos pliocénicos; neste modelo, o essencial da topografia da Serra a montante dos relevos em estrutura monoclinal seria herdada de um tempo ante-Pliocénico e a evolução quaternária seria responsável pela exumação da cobertura sedimentar; II) se, por outro lado, atribuirmos uma idade quaternária por remobilização eólica dos "sedimentos pliocénicos" (ALCOFORADO, 1981; AZEVEDO, 1982), fica impossibilitada qualquer datação relativa do nível superior e a evolução subsequente do relevo ocorre na dependência das oscilações tectónicas e eustáticas plio-quaternárias. Até que novos trabalhos possam trazer luz sobre a idade da Plataforma do Cabo, a dúvida persistirá.

A presença de níveis escalonados na paisagem favorece a atribuição de uma idade pós-pliocénica para a degradação do nível culminante e encaixe dos vales centro-orientais. $\mathrm{O}$ facto dos principais entalhes na crista monoclinal (ribeira da Pateira, Coina, Alambre, Ajuda e Cobre) já existirem aquando da deposição do Conglomerado de Belverde, constituindo afluentes do pré-Tejo, leva a colocar a primeira etapa de degradação da Plataforma do Cabo - o Nível do Cabeços - anteriormente à sedimentação dessa formação (Pliocénico médio-superior), sendo essencialmente controlada pela descida de nível de base imposta pela subsidência do Sinclinal de Albufeira (Figura 10A).

O Nível dos Cabeços é evidenciado pela diminuição de altitude para norte do bordo setentrional da Plataforma do Cabo até ao topo da crista monoclinal a oeste da ribeira de Coina, delineando uma superfície em glacis. Ao longo do troço ocidental é visível um ressalto no alinhamento do acidente de Vale Cavalo que, de acordo com Daveau e Azevedo (1980-81), terá sido responsável pelo balançamento para oeste da superfície da Plataforma. Embora a magnitude de deformação seja inferior, o ressalto observado parece indicar que este terá rejogado posteriormente à elaboração do Nível dos Cabeços, sendo a sua importância reafirmada no Quaternário pela deformação dos níveis marinhos ao longo da costa meridional.

Para leste da ribeira de Coina, o aumento da altitude do topo da costeira para 190-220 metros (255m no topo da Serra de S. Francisco) tem levado à sua corre- lação com o nível da Plataforma do Cabo. No entanto, dada a preservação da Plataforma mais a sul sobre os calcários compactos do Jurássico médio da Serra dos Gaiteiros e face à presença de falhas ativas de orientação NNW-SSE a NE-SW ao longo dos ressaltos morfológicos mais evidentes da crista monoclinal, somos levados a colocar a hipótese do sector compreendido entre a ribeira de Coina e serra de S. Francisco constituir uma deformação do Nível dos Cabeços.

Neste modelo, durante as primeiras fases de elaboração do Nível dos Cabeços, a linha divisória de águas estaria situada ao longo do topo do Formosinho e S. Luís, unindo os pontos mais altos da cadeia da Arrábida (Figura 10A). A contínua subsidência na zona do Sinclinal de Albufeira terá favorecido o encaixe da rede de drenagem, criando as interrupções na crista monoclinal que viriam mais tarde a constituir os vales das ribeiras centro-orientais (Figura 10B). Neste período, possivelmente correlativo da deposição do Conglomerado de Belverde, terá ocorrido um primeiro levantamento dos compartimentos a leste da ribeira de Coina e do cabeço do Formosinho, por rejogo de falhas de orientação NNW-SSE a ENE-WSW. Este evento tectónico está marcado pela rutura da falha de Coina ao longo do Conglomerado de Belverde (AZEVEDO, 1982).

$\mathrm{O}$ encaixe da rede hidrográfica terá perdurado durante o Quaternário inferior, alimentando os cones de dejeção de material cascalhento da Formação de Marco Furado, situados na desembocadura dos principais vales (Figura 10C). O acentuar da componente de levantamento (identificada pela deformação da Formação do Marco Furado) e o forte contraste litológico ao longo do sector oriental, terá promovido a inversão da direção de escoamento, forçando a rápida progressão da cabeceira das bacias da Ajuda e Alcube para NW e WSW, capturando a drenagem proveniente do Formosinho (e S. Luís?). Esta observação é suportada pela presença de depósitos correlativos da Formação de Marco Furado na desembocadura dos entalhes E1 e E2, permitindo situar a sua captura já no Quaternário (Figura 10D).

A análise morfométrica permite ainda concluir que o entalhe observado em E1 e E2 não pode ser explicado pelo contexto morfológico atual, obrigando a uma extensão para sul da sua cabeceira, com estabelecimento provável ao longo do Formosinho. Tendo em conta a paleo-altitude obtida para o topo da Serra $(230 \mathrm{~m})$, consideramos um uplift de aproximadamente 200 metros para um período que se situa de forma imprecisa entre 

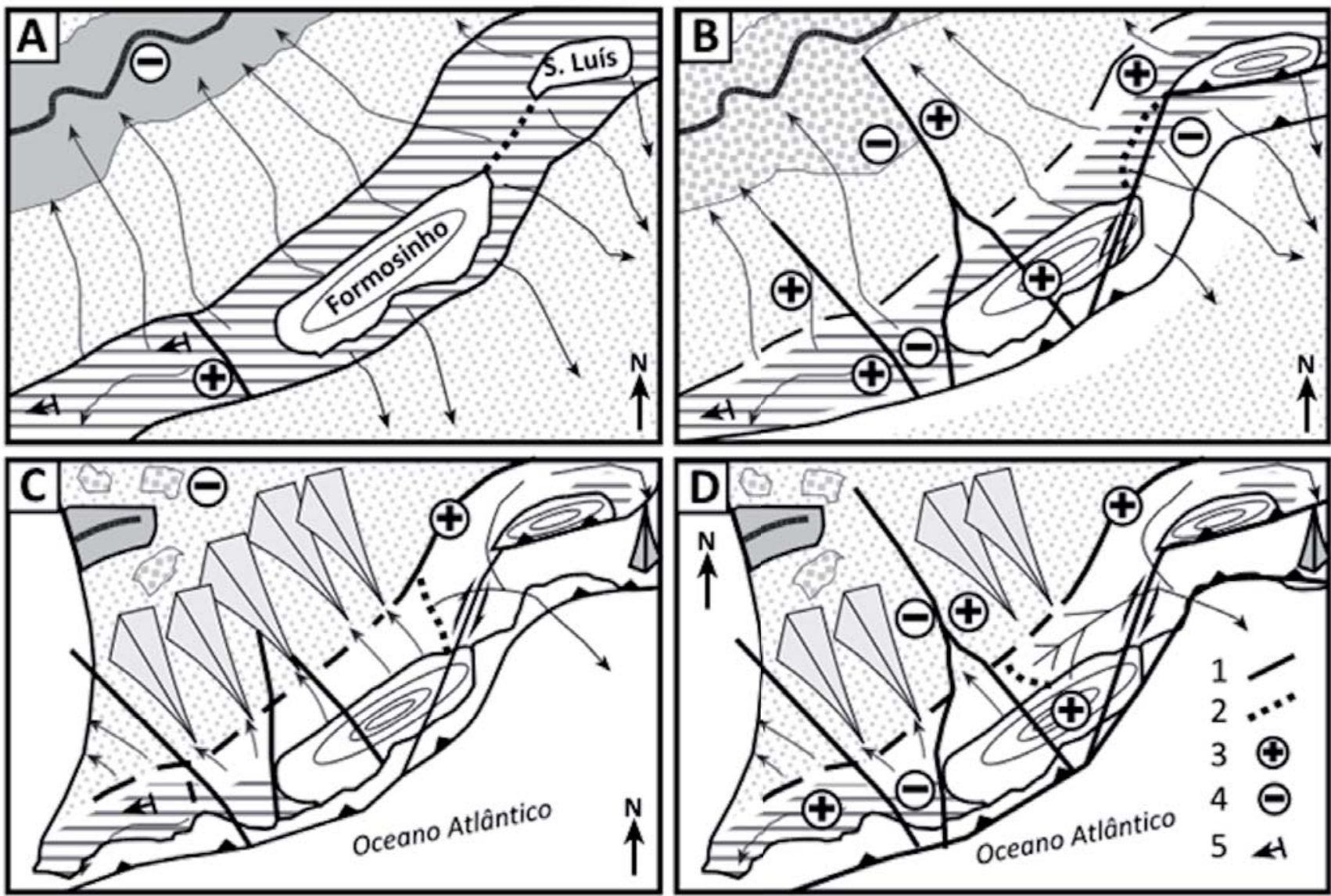

Figura 10 - Esquema proposto de evolução do relevo da cadeia da Arrábida. A) Pliocénico médio-superior - Fase inicial de degradação da Plataforma do Cabo; rejogo da falha de Vale Cavalo e balançamento para oeste; B) Pliocénico superior/Quaternário inferior - Deposição do Conglomerado de Belverde; impulso tectónico importante com rejogo diferencial de falhas de orientação NNW-SSE NW-SW e NE$S W$, acompanhado do encaixe da rede hidrográfica; erosão remontante nas bacias orientais e migração da cumeada principal para NW; estabelecimento do Tejo a norte na zona do gargalo; C) Quaternário inferior - Derrames torrenciais da Formação de Marco Furado e acentuar da migração da divisória de águas das bacias orientais; D) Reactivação de falhas de orientação NNW-SSE a NW-SE e captura dos entalhes a ocidente da ribeira de Alambre; acentuar da deformação do sector ocidental da Plataforma do Cabo. 1) Falha; 2) Divisória de águas; 3) Levantamento e 4) Subsidência relativa; 5) Direção de balançamento.

o Pliocénico e o Quaternário, traduzindo-se em taxas de uplift que podem variar entre 0.04 (base do Pliocénico $5.3 \mathrm{Ma}$ ) e $0.11 \mathrm{~mm} /$ ano (base do Quaternario - $1.8 \mathrm{Ma}$ ). Apesar do grau de incerteza, este valores estão de acordo com as taxas de movimentação identificadas para a região por Cabral (1995) e Cabral et al. (2003 e 2004).

O encaixe da rede hidrográfica nas formações quaternárias favorece a permanência de um regime tectónico de levantamento posteriormente à deposição da Formação do Marco Furado. Este processo terá sido caracterizado por um movimento de grande raio de curvatura, acentuando-se a tendência de balançamento de toda a Península para norte. No entanto, o padrão de deformação observado no sector ocidental da Platafor- ma do Cabo e nos níveis litorais, indicia uma mudança do padrão de deformação com balançamento do compartimento a oeste da falha de Vale Cavalo.

Numa análise regional, o aumento da magnitude de deformação de oeste para leste, tanto ao longo dos relevos de costeira como ao longo da vertente meridional, permite concluir que a evolução do relevo durante o período Quaternário foi controlada, tanto por um levantamento de conjunto de toda a península de Setúbal, assim como por nuances locais, associadas ao rejogo vertical de falhas de orientação NW-SE a NNW-SSE, oblíquas aos principais cavalgamentos da cadeia da Arrábida. 


\section{Conclusão}

A intensidade da deformação do substrato, a proximidade ao Oceano Atlântico e a frescura das formas de relevo fazem da cadeia da Arrábida um dos locais mais privilegiados do território português para o estudo da interação entre processos endógenos e exógenos. O presente trabalho procurou contribuir para o conhecimento da sua geomorfologia por via de aplicação de técnicas de geomorfometria e cartografia geomorfológica, focando particular atenção no papel da tectónica plio-quaternária na evolução do relevo. A análise morfométrica com recurso a sistemas de informação geográfica revelou um forte potencial na identificação de padrões de deformação tectónica regional e na deteção de anisotropias locais associadas ao rejogo de falhas ativas.

Passados setenta e seis anos sobre a "singela contribuição" de Orlando Ribeiro, grande parte das questões acerca da evolução do relevo quaternário da Arrábida continuam por responder. Embora a revolução tecnológica e científica do século XXI tenha permitido uma análise mais detalhada da paisagem e dos processos que a compõem, recorrendo a métodos robustos, visualmente atrativos e estatisticamente validados, revela-se que apenas uma reduzida parte da decomposição evolutiva do relevo se encontra efetivamente explicada. Fica no entanto expressa a necessidade de aprofundar o estudo das formações de cobertura, com recurso a métodos datação absoluta, de modo enquadrar de forma precisa cada uma das etapas de evolução do relevo aqui descritas.

\section{Referências Bibliográficas}

ALCOFORADO, M.J. (1981). Notas sobre a geomorfologia da Arrábida oriental. Linha de investigação em Geografia Física, Relatório $n^{\circ} 12$, Centro de Estudos Geográficos, Lisboa.

ANNAHEIM, H. (1956). Zur Frage der geomorphologischen Kartierung. Petermanns Geogr. Mitt. 103, 315319.

AZEVEDO, T. M. (1982). O Sinclinal de Albufeira. Evolução Pós-Miocénica e Reconstituição Paleogeográfica. Dissertação de doutoramento, Centro de Geologia, Fac. de Ciências de Lisboa, 302 p.

BOILLOT, G., MOUGENOT, D., et al. (1978) - Carta geológica da plataforma continental de Portugal, escala 1/1.000.000. Publ. Serv. Geol. Port. e Inst Hidro. Port.
CABRAL, J., (1993). Neotectónica de Portugal Continental. Tese de Doutoramento, Faculdade de Ciências, Universidade de Lisboa, Portugal.

CABRAL, J., DIAS, R. P. e BRUM, A. S. (1984). Estudo de falhas afectando formações plio-quaternárias na zona da Fonte da Telha (península de Setúbal). Comunicações dos Serviços Geológicos de Portugal. - Tomo 70, fasc.I (1984), p. 83-91.

CABRAL, J.; MONIZ, C.; RIBEIRO, P.; TERRINHA, P.; MATIAS, L. (2003). Analysis of seismic reflection data as a tool for the seismotectonic assessment of a low activity intraplate basin- the Lower Tagus Valley (Portugal). Journal of Seismology 7, 431-447.

CABRAL, J.; RIBEIRO P.; FIGUEIREDO P.; PIMENTEL N.; MARTINS A. (2004). The Azambuja fault: An active structure located in an intraplate basin with significant seismicity (Lower Tagus Valley, Portugal). Journal of Seismology, 8, pp. 347-362.

CALVET e GUNNELL (2008). Planar landforms as markers of denudation chronology_an inversion of East Pyrenean tectonics based on landscape and sedimentary analysis. In Gallagher, K., Jones, S.J., Wainwright, J. (2008). Landscape Evolution Denudation, climate and tectonics over different time and space scales. Geological Society of London, Special Publication 296, $147-166$.

CHOFFAT, P. (1908). Essai sur la téctonique de la chaine de l'Arrabida. Memórias dos Serviços Geológicos Portugueses, 89 p.

COUdÉ-GAussen G. (1981) - Les Serra da Peneda et do Gerês. Étude géomorphologique. Memórias do Centro de Estudos Geográficos, 5, 254p.

CHRISTOFOLETTI, A. (1980). Geomorfologia. $2^{\mathrm{a}}$ ed. São Paulo: Edgard Blücher. 188 p.

DAVEAU, S. e AZEVEDO, T. (1980-81). Aspectos e evolução do relevo da extremidade sudoeste da Arrábida (Portugal). Bol. Soc. Geol. Port., volume de homenagem aos Professor Carlos Teixeira, Lisboa, p. 163-180.

DAVEAU, S., BIROT, P. e RIBEIRO, O. (1985). Les bassins de Lousã et d'Arganil - recherches Géomorphologiques et Sédimentologiques sur le massif ancien et sa couverture à l'est de Coimbra. 2 Vols., Lisboa, C. E. G., 450 p.

DEMEK, J. (1972). Manual of detailed geomorphological mapping. I.G.U. Comm. Geomorph. Survey and Mapping. Prague: Czech Academy of Sciences - Institut of Geography Berno.

DRAMIS, F., GUIDA, D., CESTARI, A. (2011). Nature and 
Aims of Geomorphological Mapping. In Smith et al (eds.) Geomorphological Mapping: Methods and Applications. Developments in Earth Surface Processes, 15, Elsevier, Amsterdam, 589-593. DOI: 10.1016/B978-0-444-53446$0.00024-0$

FEIO, M. (1952). A Evolução do Relevo do Baixo Alentejo e Algarve. Tese de Doutoramento em Geografia Física, Faculdade de Letras da Universidade de Lisboa.

FERREIRA, A. B. (1978). Planaltos e Montanhas do Norte da Beira - Estudo de Geomorfologia. Tese de doutoramento. Memória do Centro de Estudos Geográficos, 4, 374pp.

FERREIRA, A.B., RODRIGUES, M.L., ZÊZERE, J.L. (1995). A cartografia geomorfológica em Portugal; in Os Mapas em Portugal, Lisboa, Ed. Cosmos, pp.183 - 222.

FERREIRA, D. (1981). Carte géomorphologique du Portugal, Lisboa, Memórias do CEG, no6, 53p.

FONSECA, A.F., ZÊZERE, J.L., NEVES, M. (2014). Geomorphology of the Arrábida Chain (Portugal). Journal of Maps, Taylor and Francis, Volume 10, Issue 1, DOI: 10.1080/17445647.2013.859637

GALON, R. (1962). Instruction to the detailed geomorphological map of the Polish lowland. Geography and Geomorphology Department, Polish Academy of Sciences, Torun.

GELLERT, J.F., SCHOLZ, E. (1960). Konzeption und Methodik einer morphogenetischen Karte der DDR. Geogr. Berich. 14, 119.

GELLERT, J.F., SCHOLZ, E. (1974). Bemerkungen zur international vereinheitlichten Legendefur mittelmassstabliche Ubersichtskarten von 1:200,000 zu 1:500,000. Stud. Geograf. Brno 41, 3236.

HELBLING, E. (1952). Morphologie des Serntales. Ph.D Thesis. University of Bern, Bern.

HOWARD, A. D. (1994). A detachment-limited model of drainage basin evolution. Water Resources Research, 30, $2261-2285$.

JOLY, F. (1963). Recherche d'une méthode de cartographie géomorphologique pour une carte des pays arides et semiarides du monde a l'échelle du 1:1.000,000. B.S. Hellé nique, Athe'ne 4, 8299.

KELler, E. e PINTER, N. (2002). Active Tectonics. Earthquakes, Uplift and Landscape. Second Edition, Prentice Hall, New Jersey, 362 p.
KLIMASZEWSKI, M. (1956). The principles of the geomorphological map of Poland. Przeglad Geograficzny 28 (Suppl.), 3240.

KLIMASZEWSKI, M. (1963). The principles of the geomorphological map of Poland. Geogr. Stud. 46, 6970.

KULLBERG, J.C., MONTEIRO, C. e ROCHA, R.B. (1995). Evolução diapírica: Modelo Cinemático baseado no estudo do doma da Cova da Mijona. IV Cong. Nac. Geol., Fac. Ciênc. Mus. Lab. Min. Geol. Univ. Porto, Mem. 4: 259-261.

KUllberG, M. C.; KUllberG, J. C. e TERRINHA, P., (2000). Tectónica da Cadeia da Arrábida. In Tectónica das regiões de Sintra e Arrábida", Memórias Geociências, Museu Nac. Hist. Nat. Univ. Lisboa, V. 2, pp. 35-84.

KULlBERG, J. C.; TERRINHA P.; PAIS J.; REIS R. P.; LEGOINHA P. (2006). Arrábida e Sintra: dois exemplos de tectónica pós-rifting da Bacia Lusitaniana. In Geologia de Portugal no contexto da Ibéria (R. Dias, A. Araújo, P. Terrinha e J. C. Kullberg, Eds.). Univ. Évora, pp. 369- 396.

MANUPPELLA, G.; ANTUNES, M. T.; PAIS, J.; RAMALHO, M. M. e REY, J. (1999). Carta geológica de Portugal na escala 1:50000. Notícia explicativa da folha 38-B Setúbal. Instituto Geológico e Mineiro, 143 p.

MARTINS, A. F. (1949). Maciço Calcário Estremenho Contribuição para um estudo de Geografia Física. Tese de Doutoramento, Universidade de Coimbra.

Miller, K.G., Kominz, M.A., Browning, J.V., Wright, J.D., Mountain, G.S., Katz, M.E., Sugarman, P.J., Cramer, B.S., Christie-Blick, N., and Pekar, S.F. (2005). The Phanerozoic record of global sea-level change. Science, 310, 1293-1298.

MONIZ, C. (2010). Contributo para o conhecimento da falha de Pinhal Novo - Alcochete, no âmbito da neotectónica do vale inferior do Tejo. Tese de Mestrado em Geologia Especialização em Geologia Estrutural, Faculdade de Ciências, Universidade de Lisboa, 128p.

PARKER, R.S. (1977). Experimental study of basin evolution and its hydrologic implications. Ph.D. thesis: Fort Collins, Colorado State University, $331 \mathrm{p}$.

PELlEGRINI, G.B., CARTON, A., CASTALDINI, D., CAVALLIN, A., D'ALESSANDRO, L., DRAMIS, F., GENTILI, B., LAURETI, L., PRESTININZI, A., RODOLFI, G., SAURO, U., SORRISO VALVO, M. AND SPAGNA, V. (1993). Proposta di legenda geomorfologica ad indirizzo applicativo, Geografia Fisica e Dinamica Quaternaria, 16 (2), 129-152.

PEREIRA, A.R. (1988). Aspectos do relevo de Portugal. Litorais 
ocidental e meridionais da Península de Setúbal. Finisterra, XXIII (46), 335-349.

PEREIRA, A.R., REGNAULD, H. (1994). Litorais quaternários (emersos e submerso) na extremidade sudoeste da Arrábida. In A. RamosPereira, J. Alveirinho Dias, M.M. Laranjeira, H. Regnauld. Contribuições para a Geomorfologia e Dinâmicas Litorais em Portugal, Centro de Estudos Geográficos, Linha de Acção de Geografia Física, L.A.G.F., 35, p.55-73.

PEREIRA, A.R., BORGES, B., SOARES, A. MONGE, SANTOS, A.P., NEVES, M. (2007). Coastal Palaeoenvironments: a balance between sea level fluctuations and neotectonics. Examples on Portuguese Estremadura, In Gómez-Pujol, L. e Fornós, J.J. (Eds.) - Investigaciones recientes (2005-2007) en Geomorfología Litoral, p. 175-177.

PIKE, R.J. e WILSON, S.E. (1971). Elevation-relief Ratio, Hypsometric integral and Geomorphic Area-Altitude analysis. Geological Society of America Bulletin, vol. 82, p. 1079 - 1084.

REBELO, F. (1978). A cartografia geomorfológica de pormenor como froma privilegiada de aplicação. Estudos : os Processos Erosivos Actuais no Litoral Norte e Centro de Portugal, Coimbra, 27p.

REGNAUlD, H., FOURNIER, J., PEREIRA, A.R. (1995). Approche quantitative de la discontinuité de l'évolution de formes littorales à différentes échelles de temps. Exemple du recul de la côte de l'Arrábida (Portugal)/Quantitative approach of a non linear and scale dependand landform evolution: rate of a retreat coastline in Portugal, Arrábida. In: Géomorphologie : relief, processus, environnement, vol. 1, n 1 . pp. 7-27.

Ribeiro, A., KUllberG, M. C., KUllberG, J. C., MANUPPELLA, G., PHIPPS, S. (1990). A review of Alpine tectonics in Portugal: Foreland detachment in basement and cover rocks. Tectonophysics, 184, pp. 357-366.

RIBEIRO, C. (1866). Descripção do solo quaternário das bacias hydrographicas do Tejo e Sado. Commissão Geológica de Portugal, Lisboa, 164 p., 1 mapa.

RIBEIRO, O. (1936). A Arrábida. Esboço geográfico, Lisboa, 1936, 94 p. Dissertação de doutoramento em Ciências Geográficas apresentada à Faculdade de Letras da Universidade de Lisboa.

RIBEIRO, O. (1968). Excursão à Arrábida. Finisterra, III, 6, pp. 257-273.

RODRIGUES, M.L., ZÊZERE, J.L. (1993). A aplicação da cartografia geomorfológica de grande escala no ordenamento e gestão do território (um exemplo do Maciço Calcário Estremenho). CEG, Estudos de Geografia Física e Ambiente, Linha de ação de Geografia Física, Rel.n³2, pp.29-45.

RODRIGUES, M.L. (2008). A Cartografia Geomorfológica: Evolução, Conceitos e Metodologias (O Mapa Geomorfológico de Pormenor e alguns aspectos de aplicação). Apontamentos de Geografia, Centro de Estudos Geográficos, 38pp.

STRAHLER, A. N. (1952). Hypsometric (area altitude) Analysis of Erosional Topology. Geological Society of America Bulletin, $63,1117-1142$.

TRICART, J. (1955). Un nouvel instrument au service de l'agronomie. African Soils 4/1, 112.

TRICART, J., (1969). Cartographic aspects of geomorphological surveys in relation to development programmes. UN/ECOSOC 9, 7583.

TRICART, J., (1970). Normes pour l'établissement de la carte geomorphologique détaillée de la France. Mém. Doc. CNRS 12, 1267.

TRICART, J. (1972). Cartographie géomorphologique. Mém. Doc. CNRS 12, 1267.

TUCKER e WHIPPLE, K. X. (2002). Topographic outcomes predicted by stream erosion models: Sensitivity analysis and intermodel comparison. J. Geophys. Res., 107.

VERSTAPPEN, H.TH. e VAN ZUIDAM, R.A., (1968). ITC system of geomorphological sur- vey (English, French and Spanish). Delft/Enschede, ITC-Textbook VII 2, 153.

VERSTAPPEN, H.TH. (1970). Introduction to the ITC System of geomorphological survey. Geograf. Tijd. 4 (1), 8591.

ZBYZWESKI, G. (1965). Carta Geológica de Portugal à escala 1/50 000, folha 38-B (Setúbal), 1a edição, Serviços Geológicos de Portugal, e Notícia Explicativa. 